University of Louisville

ThinkIR: The University of Louisville's Institutional Repository

Electronic Theses and Dissertations

$12-2018$

\title{
Counter narratives: a phenomenological study of high achieving African American male high school students.
}

De'Nay Lanise Speaks

University of Louisville

Follow this and additional works at: https://ir.library.louisville.edu/etd

Part of the Educational Assessment, Evaluation, and Research Commons, Educational Leadership Commons, Elementary and Middle and Secondary Education Administration Commons, Other Educational Administration and Supervision Commons, and the Urban Education Commons

\section{Recommended Citation}

Speaks, De'Nay Lanise, "Counter narratives: a phenomenological study of high achieving African American male high school students." (2018). Electronic Theses and Dissertations. Paper 3096.

https://doi.org/10.18297/etd/3096

This Doctoral Dissertation is brought to you for free and open access by ThinkIR: The University of Louisville's Institutional Repository. It has been accepted for inclusion in Electronic Theses and Dissertations by an authorized administrator of ThinkIR: The University of Louisville's Institutional Repository. This title appears here courtesy of the author, who has retained all other copyrights. For more information, please contact thinkir@louisville.edu. 
COUNTER NARRATIVES: A PHENOMENOLOGICAL STUDY OF HIGH ACHIEVING AFRICAN AMERICAN MALE HIGH SCHOOL STUDENTS

\author{
By \\ De'Nay Lanise Speaks \\ B.A., University of Louisville, 2003 \\ M.A.T., University of Louisville, 2005 \\ Ed.S., University of Louisville, 2012
}

\begin{abstract}
A Dissertation
Submitted to the Faculty of the

College of Education and Human Development of the University of Louisville In Partial Fulfillment of the Requirements
\end{abstract}

For the Degree of

\author{
Doctor of Education \\ In Educational Leadership and Organizational Development
}

Department of Educational Leadership, Evaluation, and Organizational Development University of Louisville

Louisville, Kentucky

December 2018 
Copyright 2018 by De'Nay Speaks

All rights reserved 



\title{
COUNTER NARRATIVES: A PHENOMENOLOGICAL STUDY OF HIGH ACHIEVING AFRICAN AMERICAN MALE HIGH SCHOOL STUDENTS
}

\author{
By \\ De’Nay Lanise Speaks \\ B.S., University of Louisville, 2003 \\ M.A. T., University of Louisville, 2005 \\ Ed.S., University of Louisville, 2012
}

A Dissertation Approved on

November 12, 2018

By the following Dissertation Committee:

Dr. William K. Ingle, Dissertation Co-Chair

Dr. Detra Johnson, Dissertation Co-Chair

Dr. Mary Brydon-Miller

Dr. Derrick Brooms 


\section{DEDICATION}

This work is dedicated to all who exhibit counter narratives in my life: My husband, three sons, my father, brother-in-law, and two nephews. You are the true essence of what it means to be Black males. Thank you for allowing me to directly or indirectly tell your story. Your example to the world and contribution to this work is recognized and appreciated. To my mother, sister, and niece...I love you more than words can describe and I appreciate your support through this process. Lastly, to EVERYONE who has

supported me, I could not have accomplished this daunting task without you. I am forever grateful. 


\section{ACKNOWLEDGEMENTS}

God, I thank you for this opportunity to use my education to improve the lives and circumstances of others. I know that there are two things in life that no one can take away-my salvation and my education. It is only through you that I have attained either. Thank you for constantly providing health, strength, courage, and PEACE. My prayer is for my life's work to align with your ministry and to be done to your satisfaction. Please let this contribution to the field of research also serve to bless someone in a way that encourages them to view African American males in a new light. I am motivated by Philippians 1:6, which declares, "Being confident of this, that He who began a good work in you will carry it on to completion until the day of Christ Jesus." Thank you for completing this work within me. I love, honor, and adore you.

Erik, thank you for sacrificing so that I could work on this degree. You are an amazing father to our boys and I am so grateful for your example to them. I could not have completed this degree without you. Thank you for your support, even on the days when you didn't feel like being a support. You did it anyway, and I love you for it! I apologize for not being present at times (literally and figuratively) and I appreciate you

for loving me anyway. When we celebrate this degree, it will be a celebration of US. $\sim$ LOYL

Mrs. Akins, I have watched you since I was a little girl. I am certain I would not be who I am without your influence in my life. I knew that if I could only be half the 
woman of God and educator you are, I would be great. Witnessing God bring your vision of Carter G. Woodson Academy to fruition was pure joy and inspiration for me. This dissertation is a reflection of your life's work and I pray you find it to be a glorious tribute on your behalf. Your work is both necessary and legendary. Thank you for your never-ending support and influence. I love you. 


\begin{abstract}
COUNTER NARRATIVES: A PHENOMENOLOGICAL STUDY OF HIGH ACHIEVING AFRICAN AMERICAN MALE HIGH SCHOOL STUDENTS

De’Nay Speaks
\end{abstract}

November 12, 2018

This dissertation examined the contributing factors to the success of high achieving African American male high school students who attend an all-male, predominantly Black, college-preparatory academy. The study took place in an urban, Midwestern school district and highlighted the lived experience and perspectives of students who have at least a 3.0 grade point average. Through the lens of Critical Race Theory, this study was an effort to bring attention to counter narratives to the otherwise deleterious image portrayed of African American males. The history and plight of the African American male is included to provide a comprehensive understanding of the African American experience. Critical examination of data revealed findings around school experiences; influencers; and subsequent perceptions, values, beliefs. The implications of these findings and potential future research are included in the latter portion of this dissertation. 
TABLE OF CONTENTS

PAGE

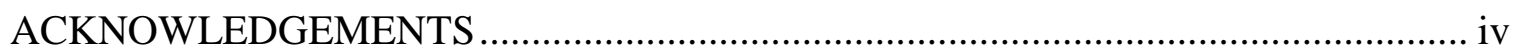

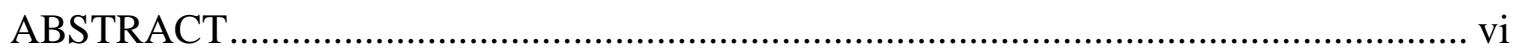

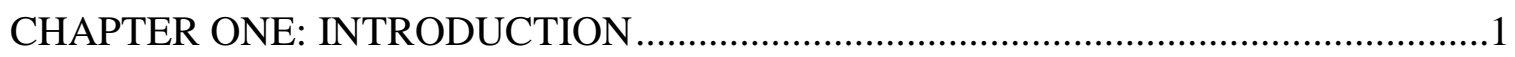

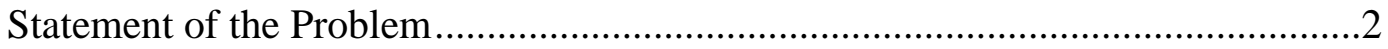

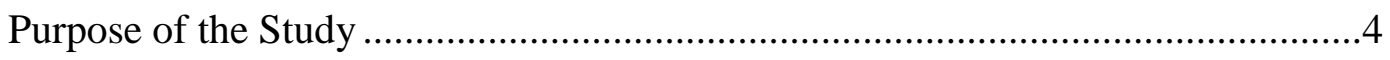

Theoretical Framework ……………………………......................................

Organization of Forthcoming Chapters ..............................................................6

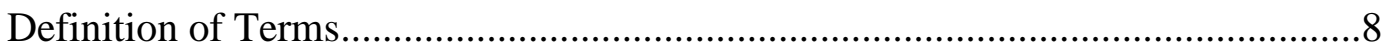

CHAPTER TWO: LITERATURE REVIEW …………………………………….......10

A History of the Black Male: A Legacy Written by Others ...................................10

The long shadow of slavery and oppression....................................................... 11

The plight of African American males. ................................................................ 14

The Miseducation of the Negro. ............................................................................ 17

The American school system and school reform efforts. ..................................... 19

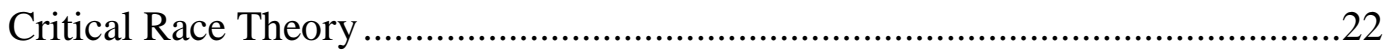

Critical Race Theory and Its Application to African American Males. ................ 23

Perceptions and Dispositions Perpetuating the Current Narrative..........................24

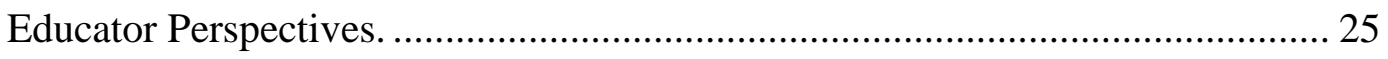

Parent Perspectives. ................................................................................... 28

Student Perspectives. ...................................................................................... 29

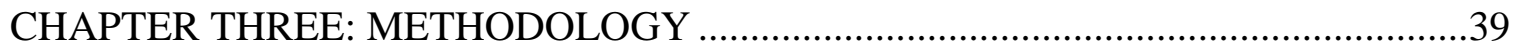

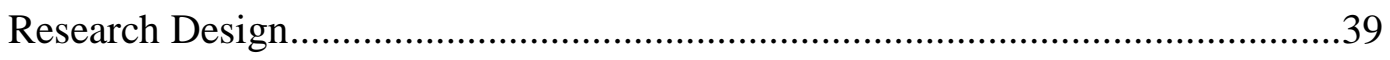

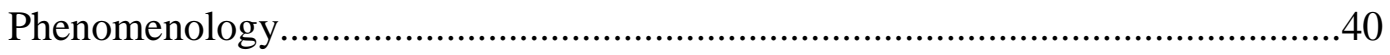

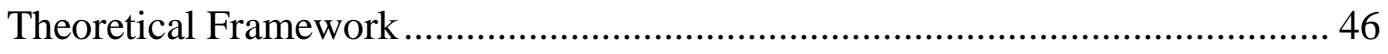




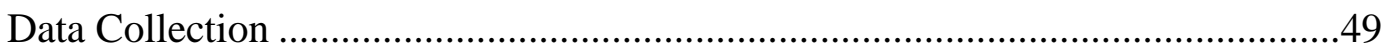

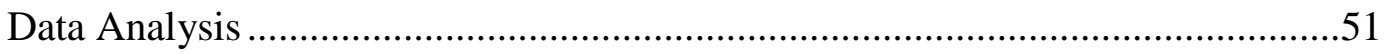

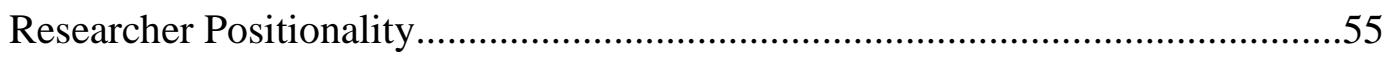

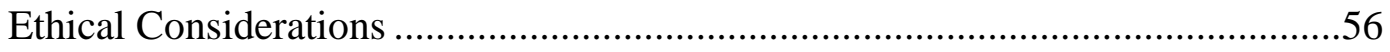

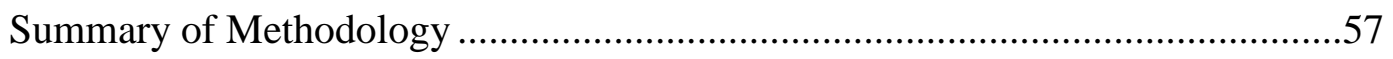

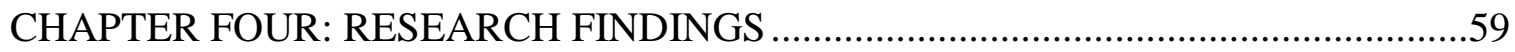

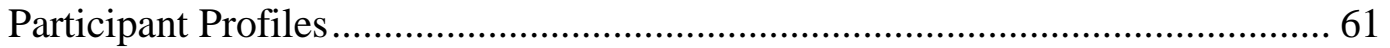

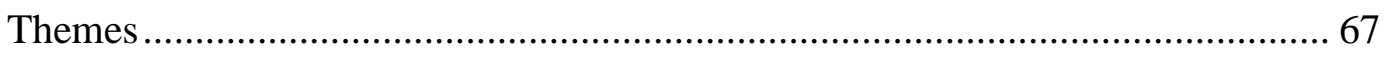

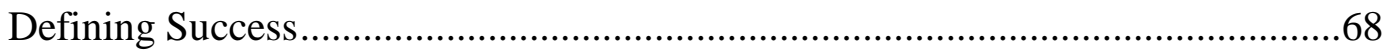

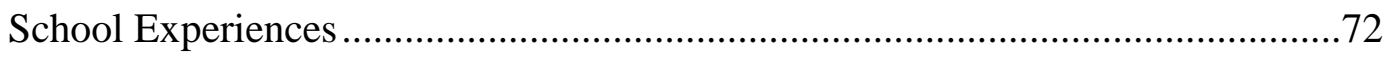

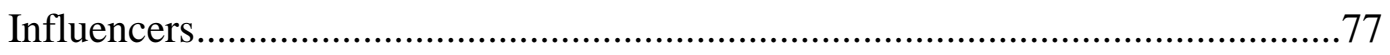

Resulting Personal Beliefs, Values, and Perceptions..............................................81

Summary of Findings and Cross-Participant Analysis .........................................85

CHAPTER FIVE: DISCUSSION AND IMPLICATIONS ………………………….....8

Background and Summary of Study ………………….................................. 88

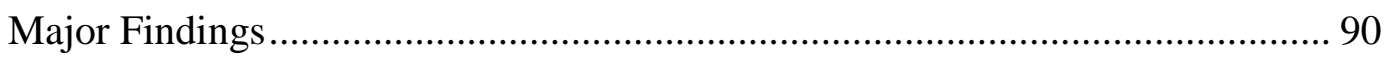

Implications for Practice ………….............................................................99

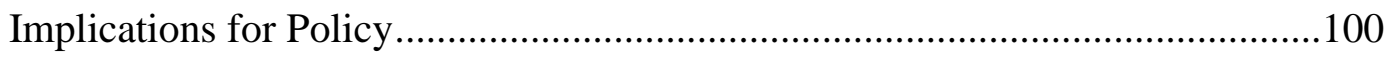

Implications for Future Research................................................................... 103

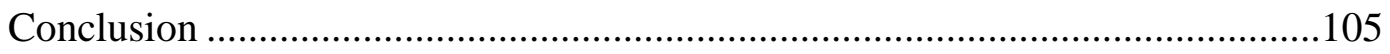

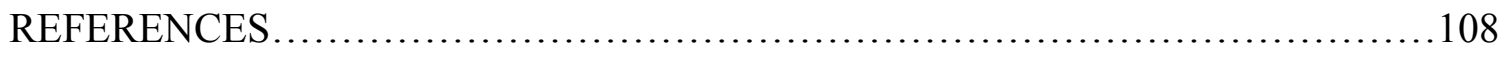

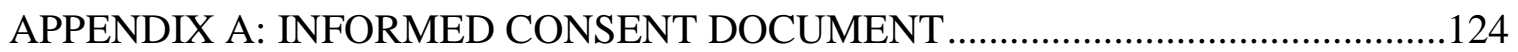

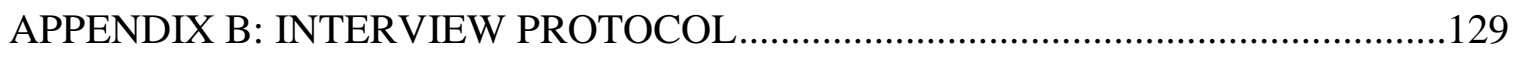

APPENDIX C: RESEARCHER POSITIONALITY …………………………...........131

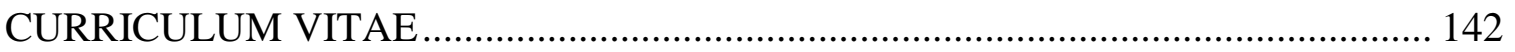




\section{CHAPTER ONE}

\section{INTRODUCTION}

In 1903, W.E.B. DuBois posed the question to Black males, "How does it feel to be a problem?" This question referred to the problem of simply being a living, breathing, and thoughtful Black body (Terrell, 2017). Regrettably, over a century later, Black people (men especially) are often viewed as a problem in society. The perceptions of mainstream America concerning African Americans in general, and African American men specifically, are often fashioned with negativity and draped in years of prejudice. These prejudices have permeated into school systems in the United States and further perpetuate these deleterious beliefs. This is evidenced by the fact that many Black students experience schooling without ever seeing people who resemble them in Advanced Placement courses, gifted and talented programs, or as their instructional leaders, yet their peers are the face of discipline policies and academic interventions (Terrell, 2017).

Harper and Davis (2012) state, "the images of Black men in our society often confine them to environments shaped by drugs, crime, athletics, and academic failure" (p. 103). African American male academic underachievement and overrepresentation in special education and prisons is well documented by many scholars. Their low rates of high school completion (Schott Foundation, 2012); the small percentage of Black males

\footnotetext{
${ }^{1}$ The words "Black" and "African American" are used interchangeably within this document to refer to Americans of African descent.
} 
earning college degrees (Sum, Khatiwada, McLaughlin, Palma, 2011); their unpreparedness for college (Bonner \& Bailey, 2006; Palmer, Davis, \& Hilton, 2009; Palmer \& Young, 2009); and the high percentage of African American males under correctional control (Alexander, 2010) are consistent and characteristic of the research on the African American condition. While much of the research offers valid, quantifiable data, it also serves to perpetuate a dominant prevailing message about African American males: there is little hope for their future. Given this reality, there is definitely a problem. The question is whether Black students are the problem or is the system the problem? If Horace Mann's (1848) assertion that "education is the great equalizer" (p. 154), is true then we must examine the United States' education system which so often produces unequal outcomes between races.

\section{Statement of the Problem}

Media depictions of African Americans are a part of a long history of racism, discrimination, and exploitation (Nasir, McLaughlin, \& Jones, 2009). Researchers have argued that the presence of the negative stereotypes make it challenging for adolescents to manage an ego-supporting identity when coping with mainstream negative imagery (Nasir et al., 2009). In these circumstances, African American youth, specifically males, are often left to cope while having few supports and may eventually engage in behaviors which perpetuate the stereotype. One of these many negative stereotypes is the underachievement of African American males (Brooms, 2016; Conchas \& Vigil, 2012; Fergus, Noguera, \& Martin, 2014; Harper \& Associates, 2014; Howard, 2014; Huerta, 2015; Milner, 2007). Much attention is given to the deficits and inabilities of African American males, but there is a scarcity of research on the many African American males 
who are high achieving and successful against all odds (Harper \& Davis, 2012). This focus on underachievement normalizes failure for African American males.

Solutions offered concerning the achievement gap often fail to consider the effects of the long shadow of slavery and oppression when analyzing origins of the current state of existence for many African American males. Much of this research neglects the fact that African Americans were enslaved for 246 years from 1619 to 1865 , then endured segregation and oppression for another 100 years from 1865 to 1965, and have only been "free" for 53 years from 1965 to 2018. Given this history, it is imperative to evaluate the generational effects of such an existence. Robinson (2000) illuminated these effects as he proclaimed:

We [Black people] are history's amnesiacs fitted with the memories of others. Our minds can be trained for individual career success but our group morale, the very soul of us, has been devastated by the assumption that what has not been told about ourselves does not exist to be told. (p. 7)

To truly ensure due diligence to the multi-layered topic of African American academic achievement, it is necessary to provide perspective and gain understanding of the actual root causes, as opposed to the symptoms, which have been present for nearly 400 years. In an effort to wholly reject the notion of the African American male as violent and unintelligible, and to effect vast change, it is important to tell another side of the story. Education can truly be "the great equalizer" (Mann, 1848) when we can transform the narrative around underrepresented groups of students and consequently change outcomes. 


\section{Purpose of the Study}

In this qualitative study, I will highlight the need to recognize counter-narratives as a framework for transforming the story and perceptions of African American males. The need to tell a more complete story of Black males is paramount to their success. There is no voice more poignant and qualified to tell the story of high academic achievement in the face of an adverse system than African American males. Therefore, the following research question will guide the purpose of this study: What experiences do high-achieving African American male high school students report as contributing factors to their academic success?

This question will be answered through semi-structured interviews with high achieving African American males who attend the Dorothy Height Academy (DHA) of Champion School District (CSD) ${ }^{2}$. This all-boys program provides curriculum and experiences through the lens of African American history. The students' unique experience in this program coupled with their academic achievement will provide a distinct perspective around contributing factors to their success.

This study is limited in that the students at Dorothy Height Academy are in a very unique learning environment which may not be feasible to replicate. As the researcher, I also have a very close relationship to the founder of the school and administrators so it is vital that I conduct this study absent of my own bias. A delimitation of this study is that the participants are purposely limited to the class of 2019. I am restricting the participants to this class of students because they will be the first class to fully matriculate through Dorothy Height Academy from sixth grade through twelfth grade.

\footnotetext{
${ }^{2}$ The school and district name are pseudonyms.
} 
These students will have the most familiarity with the experience of DHA and therefore provide a more enriched perspective.

\section{Theoretical Framework}

Given the role that race plays on the achievement of students in the United States, Critical Race Theory (CRT) is the guiding theoretical framework for this study. Critical Race Theory is a critical examination of society and culture and the intersection of race, law, and power (Decuir \& Dixson, 2004). In its applicability to the field of education, CRT can take one of two forms. It is either used a tool of analysis for structures, programs, and procedures or it is a theory of practice (Dixson \& Rousseau, 2006). In my study, CRT is used as a theory of practice.

Using Critical Race Theory as a theory of practice, this study will be guided by the five principles of CRT: centralize race and racism and its intersections with other forms of oppression; challenge dominant ideology; represent a commitment to social justice; value the lived experience of people of color; and use interdisciplinary perspectives, including education, sociology, and psychology (Kholi, 2008). Specifically, this study will focus on the examination of the intersectionality of being Black and male while navigating a school system in the United States, challenging dominant ideology by presenting counter-narratives of the lived experiences of highachieving African American males, and representing a commitment to social justice by focusing on educational equity.

\section{Significance of the Study}

In this study, I seek to bring volume to the voices of a previously silenced or misperceived population. Many high-achieving African American males'stories go largely untold. The ability to pinpoint contributing factors that positively influence these 
students to be high achievers may help educators replicate these elements across multiple settings; thus decreasing the disparity of success between African American students and their counterparts. There is an urgent, obvious need to make a tangible contribution to the research and practices that can improve the narrative and actual experiences of African American males (Howard, 2014). This study is therefore most significant to high achieving African American males. Their stories can bring clarity to strategies, experiences, and pedagogy that may help other African American males be successful; and subsequently assist in closing the achievement gap.

Helping this marginalized group has advantages for the greater good as well. If policymakers are able to recognize and reflect on systemic structures and practices within the education system that are oppressive, changes to these systems to advance the cause of equitable education may be possible. Effective research-based strategies mandated by policymakers may then translate to practitioners who can take the lead on implementation. This study will also further contribute to the scarcity of literature around high achieving African American males. Increasing the literature around this subpopulation seeks to bring awareness to the existing counter narratives, validating and encouraging other young Black achievers.

\section{Organization of Forthcoming Chapters}

In Chapter II, I provide an in-depth examination of the research literature focused on the history of Black males in America, their schooling, and to identify the need for this study. In Chapter III, I discuss the proposed case study methodology undertaken at an all-male, predominantly Black school. Chapter IV will provide analysis that results from 
the methods discussed in Chapter III. Lastly, Chapter V will summarize the conclusions and implications for policy, practice, and future research. 


\section{Definition of Terms}

The following terms are used in the context of this study:

African American. An American of Black African descent. This term is used interchangeably with "Black" for this study.

Anti-Racism Education. Aligning existing curricula with the process of deconstructing racism in schools and society (Matias \& Mackey, 2016)

Black. An individual of African descent. This term is used interchangeably with "African American" for this study.

Critical Race Theory. A theoretical framework used within social sciences that uses critical theory to examine society, its systems, and institutions as it relates to race, law, and power.

Critical Theory. A philosophical approach which seeks to confront the social, historical, and ideological structures and forces that constrain culture.

Culturally Responsive Pedagogy. Teaching strategies which incorporate relevancy and culture in student learning (Gay, 2000; Ladson Billings, 1994).

Deficit Mindset (Thinking). A thought process which relegates student performance, especially for low-income or students of color, to biological or social deficiencies such as lack of intelligence, lack of motivation, or inadequate abilities.

High Achieving. For the purpose of this study, high achieving refers to students with a 3.0 grade point average GPA or higher on a 4.0 scale.

Micro-aggression. Indirect, subtle, or unintentional discrimination against marginalized groups.

Race. A socially constructed category that differentiates ethnic groups. 
Racism. A system of privilege and oppression, a network of traditions, legitimating standards, material and institutional arrangements, and ideological apparatuses that, together, serve to perpetuate hierarchical social relations based on race (Thompson, 1997).

Segregation. The separation or isolation of a race, class, or ethnic group. 


\section{CHAPTER TWO \\ LITERATURE REVIEW}

The literature reviewed in this chapter assists in providing an examination of the history of African American people in the United States and an evaluation of the formation and intended purpose of the United States school system at its inception. This offers perspective on the origination of the achievement gap. I also consider the major reform efforts that have taken place and the subsequent effects on African Americans. These analyses lay the foundation for current negative perceptions perpetuated by various forms of media concerning the underachievement of African Americans. This review also serves as the justification for answering the research question: What experiences do high-achieving African American male high school students report as contributing factors to their academic success?

\section{A History of the Black Male: A Legacy Written by Others}

The prevailing narrative through all forms of media concerning the state of African American males in the United States is desolate. More than a decade ago, mainstream news reported close to 7 in 10 stories about Black young men and boys related in some form to crime, while coverage of young men and boys in general included only 4 in 10 stories related to crime (Cushion, Moore \& Jewell, 2007). This disproportionate rate of negative reporting continues to increase over time (Prier, 2017). The 1915 film "Birth of a Nation” portrayed Black men as villains and violent rapists. Then came the "gangster" narratives of contemporary rap music, while the 
disproportionate news reportage simultaneously portrayed Black men as perpetrators of crime; all conspiring to induce a punitive approach toward Black male students in America's schools (Prier, 2017). Harper and Davis (2012) state, "the images of Black men in our society often confine them to environments shaped by drugs, crime, athletics, and academic failure" (p. 103).

African American male academic underachievement and overrepresentation in special education and prisons is well documented by scholars also. Their low rates of high school completion (Schott Foundation, 2012); the small percentage of Black males earning college degrees (Sum, Khatiwada, McLaughlin, \& Palma, 2011); their unpreparedness for college (Bonner \& Bailey, 2006; Palmer, Davis, \& Hilton, 2009; Palmer \& Young, 2009); and the high percentage of African American males under correctional control (Alexander, 2010) saturate the research. While much of the research offers valid, quantifiable data, it also serves to perpetuate a dominant prevailing message about African American males: there is little hope for their future. While the odds may be stacked against Black males in the United States, there are certainly many Black men who triumph in the face of adversity. Understanding their success is essential to helping other African American men replicate these accomplishments. To understand any success of Black men, it is also necessary to examine their history of trial and triumph to garner a full perspective of their journey. The next section will discuss perhaps the most injurious part of the journey African American men have endured and overcome-slavery.

The long shadow of slavery and oppression. The current state of existence for many African American men reflects the manner in which a majority of their ancestors came to the Americas—as slaves brought to the New World against their will—bought 
and sold as property. Subjugation did not just happen upon African American people, but was instead intentionally ingrained in the foundation of the United States (Jenkins, 2006). Many laws and regulations were passed to ensure the African American experience was one relegated to a standard of oppression and disparagement such as the Act for Regulating Slaves (1702) which prohibited more than three slaves from meeting together; the Negro Act (1740), which denied slaves the right to move about, assemble themselves, raise food, earn money, or learn to read; and the Supreme Court's decision in the Dred Scott case (1857), which ruled that a slave, an ex-slave, or a descendent of slaves cannot be a citizen of the United States. Such laws and systems, though relegated to artifacts of our checkered history, have implications on the psyche of African American people; and hence, have vast generational effects. The United States was simultaneously progressing towards its status as a super power and building its legacy of White wealth while those who were working to build this wealth were being stripped of citizenship and later obstructed by the restraints of oppression (Jenkins, 2006).

The systems and structures of slavery were followed by a century in which the treatment of African Americans improved through the abolition of slavery in 1865, but still proved to be extremely discriminatory in the areas of education, housing, the military, employment, politics, and the legacy of Black marginalization passed down from one generation to the next. Creating systems and structures which are inclusive and mindful of Blacks is a relatively new phenomenon, particularly in the realms of education. This is substantiated by the fact that the United States has more than a 300year history of higher education; yet only 150 years ago, it was illegal for Blacks to even be taught to read (Allen, 2015). The lasting impact of such a gap is substantial. It 
reverberates throughout the modern education system, yet researchers marvel at the current academic achievement gap. This state of being for many Black men is a distinct reflection of society's inability to make substantial change for the betterment of this population (Jenkins, 2006).

Not only did slavery and oppression have vast generational effects on the forward progress of African Americans, it also paved the way for generational prejudice and derogatory perceptions of African Americans (Jenkins, 2006). These perceptions and beliefs were perpetuated through mainstream media, causing stereotypes to flourish. One of the prevailing negative images of Black men has been one of violence and criminality (Jenkins, 2006). This stemmed from years of being characterized as an animal and brute during enslavement and propagated into the Black man as a gangster or thug; a menace to society (Brooms, 2018; Jenkins, 2006). The lack of opportunity, lack of sense of hope, and lack of positive sense of self have all preceded the eventual self-fulfilling prophesy many Black men experience; then this experience is exploited by mainstream media, telling only a portion of the real story. This incomplete narrative only serves to further penetrate the wounds and deepen the struggle of African American people. As Carter G. Woodson (1933) noted, "When you control a man's thinking, you do not have to worry about his actions. You do not have to tell him not to stand here or go yonder. He will find his 'proper place' and stay in it (p. 21). Controlling the thinking of African American people through forbidding them to read and attempting to keep them ignorant has helped much of this community into their 'proper place'.

The disturbing realities of slavery and oppression are complicit to the current narratives perpetuated about African American males. From being characterized as 
animals to being vilified as unintelligible criminals, the systems and structures of the United States have long burdened and stifled Black people (Jenkins, 2006). The onus therefore, is on the people of the United States to evaluate our own perceptions and beliefs to ensure we are not furthering systems and structures of oppression. These structures which contribute to the plight of African American males are detailed in the next section.

The plight of African American males. A report by the Black Males Institute of UCLA (2017) states,

Those of us who occupy roles and positions of civic leadership have a tendency to suffer from 'deficit-attention disorder'-rather than the syndrome of Attention Deficit Disorder that is often ascribed to too many of our young men: we hyperfocus on the deficits and 'broken-ness' plaguing these young people and fail to look under the hood of the success stories emerging right under our noses. (p. 1) The negative perceptions and narratives around African American males has perhaps triggered the aforementioned 'deficit-attention disorder'. In contrast, the origination of the struggle of African American males is often ignored or misunderstood. Research suggests that existing quality-of-life indicators imply Black men are in deep trouble (Noguera, 2003). However, it could also be maintained that these men have been in deep trouble since being brought to the United States. Young Black boys have often been eaten up by the ghetto before he can master the art of survival, much less gain the basic skills needed to commence upon a successful educational career (Brooms, 2015; Powell, 2007). The weight of these common ills contribute heavily to the plight of many African American males. 
Though slavery was abolished in 1865 , racism and inequalities yet persist over 150 years later. This affects the African American male exponentially more than any other ethnic group (Noguera, 2008). Periods of change such as the abolition of slavery, the Reconstruction, Brown v Board of Education, and the Civil Rights Movement have allowed the United States to make noticeable progress with race relations; however, racism and inequities endure for many. This is evidenced by the plight of the African American male today. Toldson and Lewis (2012) noted that only 16\% of black males hold college degrees, compared to $32 \%$ of White males; African American males are 2.5 times less likely to be enrolled in gifted and talented programs, even if their prior achievements reflect the ability to succeed; Black males are three times more likely to be suspended or expelled from school than their White peers, therefore missing valuable learning time; and African American males are less likely to graduate from high school in four years than their White peers and twice as likely to drop out of high school as their White peers. These statistics exhibit many of the overwhelming obstacles many African American males must overcome in order to be successful.

Contrastingly, grave statistics are not the only indication of the Black male experience. Adichie (2009) warned against the dangers of a single story and noted that our lives and cultures are composed of many overlapping stories. All of these stories deserve to be displayed so as not to characterize groups of people with one broad stroke. In that regard, Toldson and Lewis (2012) also found that although many have reported Black males as underrepresented in colleges and universities, Black males' representation is actually proportionate to their representation in the general population. There are over two million Black males in the United States with a college degree, over one million 
Black males currently enrolled in college, Black families donate $25 \%$ more of their incomes to charities than White households, and Black males are one of the largest percentages of American veterans (Schott Foundation, 2015). The polarity of these statistics indicates a systemic problem as opposed to a problem with Black males. The system consistently provides a monolithic narrative while the counter narrative is largely unknown. Much of the United States would prefer to focus on the negative indicators than understand how systems are creating these negative situations for many people. This focus on underachievement normalizes failure for African American males. Noguera (2008) described this normalization in New York City Public Schools:

The trouble with Black boys is that they [al]most never have a chance to be thought of as potentially smart or talented or to demonstrate talents in science, music, and literature. The trouble with Black boys is that too often they are placed in schools where their needs for nurturing, support, and loving discipline are not met. Instead they are labeled, shunned, and treated in ways that create and reinforce an inevitable cycle of failure.

(p. xxi)

There are many high-achieving African American males whose stories are largely untold (Brooms, 2017). The ability to pinpoint contributing factors that positively influence these students to be high achievers can help educators replicate these elements across multiple settings; thus decreasing the disparity of success between African American students and their White peers. There is an urgent, obvious need to make a tangible contribution to the research and practices which can improve the narrative and actual experiences of African American males in America (Howard, 2014). This need has been 
exacerbated by practices prevalent throughout the history of African American schooling as detailed in the next section.

The Miseducation of the Negro. Carter G. Woodson (1933) declared, "The education of the Negroes, then, the most important thing in the uplift of Negroes, is almost entirely in the hands of those who have enslaved them and now segregate them" (p. 35). This statement still rings true when reflecting on the education of Black people in the United States. Woodson (1933) further outlined where we must begin in order to gain full perspective of the education of the Negro:

To point out merely the defects as they appear today will be of little benefit to the present and future generations. These things must be viewed in their historic setting. The conditions of today have been determined by what has taken place in the past, and in a careful study of this history we may see more clearly the great theatre of events. (p. 9)

Even though Woodson wrote these words 85 years ago, the message is yet relevant even at the current time. In order to understand how to progress in educating Black students, it is necessary to examine the history of their schooling in the United States juxtaposed with the history and persistence of racialized systems and structures.

In viewing the historic setting of enslavement, it was against the law for Black people to learn to read. Simultaneously, the common school movement began, which served as the historical antecedent of the United States public school system (Labaree, 2010). This system was produced out of the desire to preserve the republic while also capitalizing on the economic growth experienced during this time. Observably, if slaves were forbidden from being able to read, this public school system was not created with 
them in mind. Rather, slaves were the catalyst behind the economic growth-a commodity to be used. African Americans during this time were viewed as a human being of lower order, only useful when they were the hewer of wood or drawer of water (Woodson, 1933). The common school movement, which basically created the United States public school system, was not created with Black students in mind; yet remains intact today with only modest additions or alterations (Labaree, 2010). This has major implications for the how the system (mal)functions in relation to Black students. Education reformers caution against the prolonged existence of the common school movement because it illustrates how the organizational machinery of a school system created for one purpose can make it ill-suited for other purposes (Labaree, 2010). The history of the United States and its public school system is filled with paradoxes. These have endured, and the present-day school system is one that provides both access and advantage, promoting equality and inequality (Labaree, 2010, p.3). Since its inception, the public school system was designed without consideration for the African American student and in many cases, continues to operate in this same manner.

One of the reasons the education of African American students was and is so important is because it can be a determinant of the trajectory of a student's life. In essence, the education system and educators therein have major influence and control over the path a student may embark upon. Proponents of slavery and oppression were well aware of the impending impact of education and therefore attempted to keep slaves ignorant by forbidding them to read and establishing a whole school system without them in mind. Woodson (1933) professed, "The education of the Negro, then, becomes a perfect device for control from without" (p. 45). In many cases, the miseducation of 
Black people was due to the lack of formal education to maintain the locus of control. Miseducation also came in the form of misinformation or mischaracterization. As Woodson (1933) explains:

If you teach the Negro that he has accomplished as much good as any other race he will aspire to equality and justice without regard to race. Such an effort would upset the program of the oppressor in Africa and America. Play up before the Negro, then, his crimes and shortcomings. Lead the Negro to detest the man of African blood-to hate himself. With the truth hidden there will be little expression of thought to the contrary. (p. 88)

Accordingly, miseducation was intentional and visceral. The effects of this miseducation are reflected even today as African American people as a whole, and African American students specifically, work twice as hard to get half as far in society and within the United States school system.

The American school system and school reform efforts. The aforementioned common school movement essentially created the United States public school structure as we know it. The second major reform movement for the United States' public school system was the progressive movement. This movement, occurring during the first half of the Twentieth Century, sought to bring many changes to United States society, including its educational systems. A focus on adapting education to the developmental and individual needs of students, accommodating the influx of immigrants, and reconfiguring secondary education were of optimal concern (Labaree, 2012, p.5). Many progressives labored on behalf of these ideals; yet the education of Black children was still not of general interest. During this time, Black people taught each other how to read and write 
(Jenkins, 2006). Few slaves were literate, but those who were literate taught others how to read, which furthered the will to become literate. African Americans understood that possessing the ability to read was the pathway to freedom. Story-telling, music, and crafts were also used to transfer knowledge during this time. Eventually, Black people were educated in "free Black schools" developing and utilizing curriculum as determined by the Black educators who would lead the schools (Jenkins, 2006).

A series of reforms took place from the 1950s to the new millennium.

Desegregation efforts of the 1950s and 1960s gradually grew into a movement to ensure America's schools were inclusive (Labaree, 2010). De jure segregation by race came to an end and efforts to guarantee gender equality were the results of this movement. Students with disabilities also were championed during this time. However, the practice of misdiagnosing Black students as having disabilities led to exponential increases in special education within segregated settings (Wright, Crawford, \& Counsell, 2016). Consequently, many African American students were misidentified as having a disability in an effort to continue segregating them from White students. African American students were allowed to attend schools with White students by law, but the racist treatment and perceptions continued. Coleman (1966) offered seminal research examining the inequities of educational opportunities throughout the United States and especially the South since desegregation. This report, mandated by the Civil Rights Act of 1964 and later known as the Coleman Report, had major flaws in methodology yet laid the foundation for emphasizing the disparities in educational practice between racial and ethnic groups (Camera, 2016). 
The school standards movement began in the 1980s, the school choice movement in the 1990s, No Child Left Behind (NCLB) was enacted in 2002, and then the Every Student Succeeds Act (ESSA) was sanctioned in 2015. ESSA reauthorized the 1965 Elementary and Secondary Education Act to ensure every student achieves. While NCLB sought to use curriculum guidelines and high-stakes testing to help raise academic achievement of schools and to close the achievement gaps based on ethnicity, gender, and socio-economic status, it also shined a bright light on disparities in achievement, especially between White and Black students. This stimulated the focus on the achievement gap for many education researchers and consequently proliferated the narrative on the grim state of existence for African American male students (McMillen, 2004). The expectation was that NCLB would provide additional support and resources for school improvement; however, high-stakes testing became the focus. This only produced lists of failing schools but no real solutions (The Hechinger Report, 2016). ESSA was consequently touted as giving more control back to states to make decisions about accountability and how to support failing schools and de-emphasized test scores. Civil rights groups have argued, however, that giving states more control has not historically proven beneficial to students of color (The Hechinger Report, 2016). The effects ESSA may have on African American students remains to be seen.

The reforms of the United States education system all have sought to improve education in one manner or another. However when creating and implementing reform initiatives, education professionals, policymakers, and social institutions must come together to examine the rudiments of the entire educational process before evaluating the product, otherwise reproducing the achievement gap is inevitable (McMillen, 2004). 
While the public education system aims to tackle the myriad list of issues ailing Black males through a focus on closing the achievement gap, it remains verifiable that much of this population succeeds in spite of schools and not because of them. Many of these young men exhibit unmatched resilience allowing them to persevere in the face of adversity (Howard, 2014). When there seem to be surface efforts to save the Black male without considering the history of the Black male in America, it makes one wonder whether their failure is by design. A close examination of the underlying systems and structures which may be undermining the education process for some students would prove beneficial. The next section offers a critical lens for doing so.

\section{Critical Race Theory}

Critical Race Theory (CRT) is derived from a plethora of literature based in law, sociology, and history (Bell, 1987, 1992; Delgado, 1995; Delgado \& Stefancic, 1993, 1994). Education researchers (Ladson-Billings, 1996, Solorzano, 1997) applied the tenets of Critical Race Theory to educational discussions about access and equity and thus currently, many social science researchers use Critical Race as a lens from which to view the inherent and ingrained racist systems and structures which are pervasive in the United States society. CRT represented a paradigm shift in the dialogue around race and racism in education (Solorzano \& Ornelas, 2002). CRT seeks to identify, analyze, and transform aspects of education that uphold subordinate and dominant racial positions through the following five elements: (a) the centrality of race and racism and their intersectionality, (b) challenging dominant ideology, (c) a commitment to social justice, (d) the centrality of experiential knowledge, (e) the transdisciplinary perspective (Solorzano \& Ornelas, 2002). Challenging the dominant ideology of the uneducated 
African American male contributes to the purpose of my study and provides an opportunity to highlight the existing counter narratives. CRT has many implications for African American males, which are detailed in the following section.

\section{Critical Race Theory and Its Application to African American Males. Critical}

Race Theory's application in educational research maintains the notion that United States educational institutions marginalize people of color (Solorzano \& Yosso, 2002). Researchers that apply CRT often question whose stories are majoritarian within the educational context and whose stories are distorted and silenced. The history of the United States has exposed White middle- and upper-class stories as honored in the educational setting, whereas the stories of people of color are distorted or silenced (Solorzano \& Yosso, 2002). African American males have been marginalized throughout their history in the United States and their place in the education system has been an afterthought at best. The systems and structures of racism and oppression have preserved a negative narrative keeping Black men from accessing education that meets their needs. Many succeed in spite of the public education system, not because of it. The work of Critical Race Theory is essential and necessary because as Solorzano and Yosso (2002) suggest, even though social scientists tell stories under the guise of "objective" research, the tales they produce often uphold deficit, racialized notions about people of color. Critical Race Theory affords researchers the opportunity to counter deficit storytelling so that these racialized notions can be debunked.

Recent attention on the underachievement of African American males has led to initiatives for all-male schools that have found unique methods of addressing the needs of Black males (Laing \& Brown, 2016). However, this upsurge has sparked debates 
concerning the constitutionality of majority-Black male schools. Advocates of such institutions argue these schools are in a unique position to help Black male youth by pushing past stereotypes, incorporating culturally responsive pedagogy, and creating systems tailored towards their needs. Critics point out that there is no empirical support for this view there is little data on the effects of such schooling, in particular for students of color (Laing \& Brown, 2016). Ultimately, No Child Left Behind (NCLB) made the proliferation of such schools possible as it allowed for the establishment of single-gender schools. Single-gender schools have the potential to provide nurturing spaces for the nuanced experiences of African American males where their unique challenges are understood (Laing \& Brown, 2016). Critical Race Theory is associated with this work in its focus on honoring and avowing the experiences of people of color as opposed to distorting and silencing these experiences.

\section{Perceptions and Dispositions Perpetuating the Current Narrative}

Perceptions regarding African American achievement have shifted in the $21^{\text {st }}$ century as national attention has been given to closing the academic achievement gap. In the 1980s and 1990s, racial gaps in achievement and intellectual ability were literally attributed to innate genetic differences between population groups, and were therefore regarded as acceptable or natural phenomena (Frederickson, 1981; Hernstein \& Murray, 1994). Altering patterns of achievement was not regarded as feasible nor desirable as recently as just 36 years ago. In essence, the attitudes, beliefs, and perceptions about African American achievement were rooted in a deficit mindset and many educators even to this day have these same views that are associated with the vestiges of racial discrimination (Quin, 2016). 
As the paradigm has shifted, many have embraced the need to "save" Black males in an effort to increase academic achievement and graduation rates. However, in order to truly change outcomes and circumstances for Black men, a paradigm shift in the way they are seen and understood is necessary. The current image of the Black male as an underachieving, criminal, brainless athlete is literally destroying Black men and boys (Noguera, 2014). As asserted previously, racism is a pervasive element of United States society. Perceptions and subsequent actions are often predicated on underlying racist views, whether overt or covert (Jenkins, 2006). In relation to how this interplay is exhibited within the classroom, Noguera (1997) proclaimed the following:

Because of an internalized belief in racial stereotypes and the influence of the social label of Black man as villain, many teachers, White and Black, hesitate to engage and interact in a close and nurturing way with Black boys and often fail to provide them with superior educational service. (p. 144)

This assertion is evidence of the disservice many African American students experience as a result of misperceptions based on racialized notions. The following section specifies how educator perspectives can have a vast impact on student achievement or underachievement.

Educator Perspectives. The relationship between teachers and African American students is heavily documented, usually attributing cultural differences between African American students and teachers to the struggle to build and maintain relationships (Allen, 2015). Teachers' low expectations for African American males, their role in referrals contributing to the overrepresentation in special education, and school suspensions are common themes in the research literature (Artiles 2003; Delpit 1995; Harry \& Klinger 
2006; Milner, 2005; 2008). These acts of racism, which Black students experience in school, have powerful effects on student self-efficacy and opportunity to learn (Allen, 2014). Racist perspectives have played a historical role in the underachievement of Black students since the racial desegregation mandated by Brown vs. Board of Education (1954). While the law provided Black students with access to educational resources offered in previously White-only schools, the prejudiced and stereotyped beliefs of White teachers negatively impacted the achievement of Black students, especially Black males (Hooks, 2001).

The monolithic story promoted in the United States concerning the education of Black males is recapitulated through state standards, national assessments, and daily classroom teaching (Wiggan \& Watson, 2016). While classroom demographics shift away from a White majority, the educational workforce is still largely White and classroom teaching often lacks culturally responsive pedagogy (Wiggan \& Watson, 2016). Race is certainly no indication of effective teaching strategies, however, the underrepresentation of minorities in the teaching profession coupled with the lack of culturally responsive teaching is a major problem in public and private schools (Milner, 2005). In addition to culturally responsive pedagogy, anti-racism education is necessary to align existing curricula with the process of deconstructing racism in schools and society. Specifically, anti-racism education is a response to "hegemony", or the way in which dominant groups universalize their interest over all other groups which reifies White, European, middle-class ethos (Wiggan \& Watson, 2016). Hegemony marginalizes and underserves students of color; therefore, anti-racist curriculum responds to this marginalization by examining the role of education in producing race, gender, and 
class inequities in society (Dei, 2003). This supports and augments the work of Critical Race Theory. In order for this to occur, however, teachers must be willing to reflect honestly upon their own beliefs and value systems in order to influence their personal perspectives and subsequent pedagogy.

One of the many ways in which educator perspectives and pedagogy have impacted Black students disproportionately is through the lack of referrals for Advanced Placement coursework. Due to low expectations and misperceptions of African American youth, especially males, these students are often not recommended for Advanced Placement classes. Many times the referral process is based on teacher or counselor nomination. This process is flawed because it relies on teachers or counselors to be gatekeepers who make judgements based on their own preconceived ideas of what characteristics Advanced Placement students should exhibit (Bonner, 2000). This mode of identification has proven to be ineffective and has exacerbated the problem of underidentification of African American students because nominations are often based on the subjective parameters of White, middle-class society (Bonner, 2000).

Taliaferro and DeCuir-Gunby (2008) confirmed there is a dearth of African American students in Advanced Placement courses. They explored the underrepresentation of African American students in advanced classes, especially Advanced Placement classes and specifically examined educator's perspectives while using literature concerning Advanced Placement programs, parental and teacher support, and school belonging. This lack of participation in advanced curriculum is a significant inequity concern because it leads to placement in comprehensive or remedial classes, which does not fully prepare students for college, further expanding the academic 
achievement gap (Taliaferro \& DeCuir-Gunby, 2008). The theoretical framework of operational citizenship was presented as a guiding paradigm for this case study. These researchers concluded that in order for students to feel a sense of belonging and take ownership of their education, they must be treated like and perceive themselves to be full citizens of the educational system. Taliaferro and Decuir-Gunby (2008) contend that when students are given all the responsibilities of the system but not afforded the rights of the system, they are not operational citizens of the school polity. These children are then blamed for their lack of educational success while simultaneously being subjected to low expectations and denied inclusion. From just one educator's negative perceptions, many damaging outcomes can and do occur for numerous African American students. These damaging outcomes also have implications for the parents of these students which is detailed in the following section.

Parent Perspectives. African American parents are often perceived as lacking a desire to be involved, aloof, and uninterested (Allen, 2015). However, Black parents are well aware of the many challenges their children may have to contend with, not only academically but in daily life (Rowley, Ross, Lozada, Williams, Gale, \& Kurtz-Costes, 2014). African American families are usually concerned about their students' education, but they sometimes lack the social, cultural, educational, and fiscal capital to assist them in navigating the system (Ford \& Moore, 2013). Parents are also aware that many teachers and community members of authority have negative views of Black boys and therefore may view them as an antagonist. Forty-four percent of urban parents report that they feel unwelcomed in schools (Ford \& Moore, 2013). This can be due to various reasons such as previous negative experiences with their own schooling or the inability to 
relate culturally to school personnel. These underlying (mis)perceptions often attribute to the oppositional relationships experienced by parents which can lead to these parents being under-informed; especially concerning programming such as Advanced Placement (Rowley et al., 2014).

The extent to which African American families are involved in school also varies by family income and family structure. Ford and Moore (2013) also reported that 49 percent of Black children live in single-parent homes, with poverty usually accompanying this situation. Often in these instances, adult presence is minimal, resulting in less structure and discipline for these students. Also, African American males rarely spend unsupervised time studying or participating in school-related activities, causing them to suffer academically and socially (Ford \& Moore, 2013). The degree to which the parents of such students can participate in their education influences their academic achievement directly and can perpetuate these parent's feeling of disconnectedness from the school. When this feeling is present, a parent is less likely to initiate engagement within the school community (Ford \& Moore, 2013).

Student Perspectives. The media play an important part of children's lives, particularly African American children, who reportedly use an average of 9.75 hours of media daily (Gordon, 2016). As these youth consume various forms of media such as television, music, computer, video games, print media, movies, and social media, they are concurrently exposed to numerous messages about social roles and norms, which include stereotypes (Kirsh, 2010). Many of these same stereotypes perpetuate negative teacher perceptions about African American students and in some cases cause students to fall into the self-fulfilling prophecy. Also, parents are aware of these stereotypes and often equip 
their children with messages of racial pride while being explicit about the barriers racism can create and emphasizing the need to be racially resilient (Allen, 2014). In addition, negative stereotypes can reduce the performance of individuals who belong to stereotyped groups (Dzaferagic, 2016). Negative stereotypes can cause members of the stereotyped group to become self-conscious about their performance, which may hinder their ability to perform at their best. Furthermore, students from stigmatized groups are sometimes bothered by the possibility of being negatively stereotyped, which results in a feeling of pressure to perform in a manner which does not confirm the stereotype. This pressure can then impair their academic performance, creating a self-fulfilling prophecy known as stereotype threat (Dzaferagic, 2016). Clearly, stereotypes can be dangerous. They not only can shape our attitude towards a group but they can also shape the behavior of that group; causing us to see what we want to see. It is therefore essential to consider the potential impact of such stereotypes on the academic achievement of African American youth.

Another important factor when researching high achieving African Americans is to determine the meaning of "achievement" to this group of students. Wiggan's (2014) research intended to develop a meaning of achievement from the students' perspectives. A qualitative study on African American students attending a public urban university in southern United States was conducted. The study illustrated how the sampling of students challenged the accepted achievement prototype (grades and test scores as achievement) and created their own sense of achievement. The students' narratives suggested their perspectives on achievement were based on personal growth and development, meeting parental expectations, and social responsibility. The students did not rely on standardized 
test scores and grades to prove achievement because they did not believe standardized tests were valid and indicated inequity among schools makes grade point averages untenable. Students did however recognize the need to 'play the game' of doing well on standardized tests and grading in order to accomplish their goals.

Wiggan (2014) also illustrated that students' meaning systems may differ from that of schools, and that teachers should be sensitive to this issue. Students may continue to meet the challenges of standardized tests and grading practices with success, but would also benefit from diverse assessment measures such as dialogic methods and communitybased assessment. Wiggan (2014) highlighted an interesting concept in that the students in the study were all high-performing by traditional measures, yet they still did not entirely embrace the notion that their standardized tests scores and grades reflected their achievement (Wiggan, 2014). For this group of students, being classified as highachieving was not justified by performing well on the very tests used as evidence in the on-going negative narrative being depicted.

Sankofa, Hurley, Allen and Boykin (2005) also studied student perspectives while investigating Black students' academic attitudes toward high-achievers to determine whether cultural expression played a role in their perspectives. Sankofa et al.'s study extended research by Marryshow (1992) that investigated African American students' attitudes toward four high achievers who differed in their approach to high achievement. This study found that Black children were accepting of their high achieving peers except when those peers' achievements reflected attitudes and behaviors incongruent with their own cultural orientations. Sankofa et al. (2005) focused on students' academic attitudes whereas Marryshow (1992) assessed students' social attitudes. Sankofa et al.'s findings 
were consistent with Marryshow's (1992) study, finding that the children give more favorable ratings toward African American cultural high achievers than those of mainstream cultural high achievers. Sankofa et al. (2005) found that students endorsed all of the high achievers no matter the cultural orientation, however children's ratings for the African American cultural high achievers were significantly more favorable than their ratings for the mainstream cultural high achievers. Sankofa et al. is useful in further understanding the intricacies related to Black children's perceptions of academic achievement. The findings contradict the notion that African American children entirely reject academic achievement and indicates the underlying cultural orientations of high achievement temper African American children's attitudes toward individual high achievers. With this research we are able to answer the question of whether solving African American children's educational struggles warrants changing something about the children or changing something about schools.

Boykin and Allen (2003) argue that we need to change our pedagogy as opposed to altering children's behaviors and attitude. In the United States, pedagogy is founded on dominant cultural ideals and is set up to reward behaviors that are consistent with those precepts, which is also known as hegemony. Academic success is therefore contingent on the acceptance of these dominant cultural values, which are at times incongruent with the culturally rooted value systems that African American children learn at home and in their communities (Boykin \& Allen, 2003). According to Boykin and Allen (2003), the problem is not Black children's attitudes towards achievement in general but the failure of schools to embrace and reward a larger set of values and behaviors in schools. If opportunities for culturally relevant expression enhances 
academic performance, it would stand to reason that the lack thereof may promote negative attitudes towards performance (Boykin \& Allen, 2003).

Finn's seminal (1989) work postulated that an identification-participation model accounts for school withdrawal among African American males. Finn's model suggested students must identify with the school to at least a minimal extent and feel they belong as part of the school. Finn also hypothesized students must believe themselves to be welcomed, respected, and valued by others or they may begin the gradual disengagement process with dropping out being the final step (Goodenow \& Grady, 1993; Quin, 2016). All across the United States, we see Finn's (1989) hypothesis substantiated by African American males who perceive themselves unwanted, Black males who cannot relate to their teacher or the curriculum, and who feel displaced. These factors lead to the disproportionate suspensions, expulsions, and drop-outs which are heavily documented (Toldson \& Lewis, 2012). It stands to reason that eliminating those barriers, all of which are based on educators' misguided perceptions, would lead to an increase in achievement for African American males.

Ford and Milner (2005) maintained the importance of listening to students as the most effective way to determine what must be done to ensure the education of African American students is relevant, meaningful, personal, and empowering. This reinforces the belief in 'nothing about us, without us' (Wright, Crawford, \& Counsell, 2016). Principally, this quote means you cannot change the barriers shaping the schooling context and improve education for students, particularly African American students, without listening to them and their perceptions of their own schooling. 


\section{Counter Narratives}

The Schott Foundation (2012) contends that Black males in the United States have been cast in a far too negative light given their contributions to family, community, democracy, economy, thought leadership, and country. This narrative has become prevalent due to a focus on the deficits of the United States school system. While these deficits are important to highlight because they shed light on the many inequities facing students of color; it is also important to emphasize the counter-narrative to underscore the resiliency being displayed by many students across this country (Hampton, 2014). Montecinos (1995) offered a poignant interpretation of the detrimental effects of a master or dominant narrative:

The use of a master narrative to represent a group is bound to provide a very narrow depiction of what it means to be Mexican-American, African-American, White, and so on...A master narrative essentializes and wipes out the complexities and richness of a group's cultural life...A mono-vocal account will engender not only stereotyping but also curricular choices that result in representations in which fellow members of a group represented cannot recognize themselves. (pp. 293-294)

The master narrative is synonymous with the dominant narrative, which are both contributors to hegemony prevailing throughout public and private schools. Racism in and of itself allows these monolithic accounts to become reality and take on a life of their own. It is within the context of racism that singular stories around the low educational achievement and attainment of students of color are told and subsequently unacknowledged White privilege helps maintain these racist stories (Solorzano \& Yosso, 
2002). The need to expand knowledge of counter narratives assists in changing perceptions, beliefs, and expectantly actions towards individuals who are usually the subject of discrimination.

Harper (2015) used photographic data from a study of 325 college-bound juniors and seniors attending 40 public New York City high schools to explore the visual counter narratives of young men of color. After conducting the study, Harper suggested that perhaps he should have named the article simply, Seeing Success because much of what he saw within the schools was hiding in plain sight (Harper, 2015). The research literature on Black males is chronically lopsided, largely due to the deficit mindsets which many researchers embody. Successful young students of color can easily be found, researched, and learned from if there is a will to do so. While researchers are so quick to document the detriments and impairments of students of color, it would prove more beneficial to also document and raise consciousness about the policies, practices, and structures which undermine the success of the same (Harper, 2015).

The schools of Harper's (2015) study are unlikely to be extreme outliers. Like most urban schools, the schools of his study had issues. However, it is likely that every urban school which is usually discussed as failing, does some good that can be seen, documented, and explained by stakeholders and leaders (Harper, 2015). With that being said, Harper (2015) questions: Who are the students who manage to thrive and go to college from these schools despite high teacher turnover and excessive levels of violence and what role did school officials play in the actualization of their goals? These questions were posed as models and as a way to view schools in a more beneficial manner. This manner is not only more beneficial to the students and staff of these 
schools, but also for policy-makers and the general public in order to replicate methods of success. Otherwise, the one-sided narrative in which many urban schools are discussed in the media and education research will continue to cyclically reproduce problems. A counter narrative of success, even in small increments, is a powerful testament to hope for the future.

Consequently, Brooms' (2016) study of 20 Black male graduates of an urban secondary charter school, focused on the perceptions and experiences of these young men in relation to their academic success and further aspirations. The students attended Douglass Academy, a college-preparatory, ninth through $12^{\text {th }}$ grade school in an urban, low-income community. This charter school is a single-sex school with $75 \%$ of its students eligible for free or reduced lunch and maintaining a 90\% graduation rate. In total, 20 Black male graduates of the school were interviewed using semi-structured interviews to ascertain their perceptions concerning their experiences at this school. Many of the students entered the school apprehensive about this experience yet simultaneously valuing educational attainment. All of the students identified belongingness, through school culture and relationships with teachers, as critical to their academic success (Brooms, 2016). The students also noted that Douglass embodied a positive school climate and environment and helped them to develop pride in themselves and their work. Student self-efficacy was enhanced through the welcoming and supportive atmosphere. The students had access to college campuses, internships, and extra-curricular activities, which helped them to be engaged in the life of the school. This study helped to corroborate the work of other researchers who have identified the value and importance Black males place on education (Harper \& Davis, 2012; Howard 
2014.) Giving more credence to Black males perspectives on their educational attainment can help inform us of opportunities to broaden various characteristics for academic success such as motivation and resilience (Brooms, 2016). The participants of this story are academically successful Black men, a visual of the counter narrative and a treasury of knowledge on how to generate more success stories.

The literature on counter narratives relative to high achieving African American male high school students is limited. One of the glaring absences of much of educational research focused on African American males is that it has not included firsthand accounts from this population about their experiences with schooling (Howard, 2014). The value of this experiential knowledge is immeasurable in relation to determining how systems and structures impede or advance learning for this Black males. Compounding research on Black males has involved understanding how the attitudes and actions of adults in their lives correlate to their academic outcomes. These perspectives ignore African American males' co-construction and processing of their own experiences; therefore, the need for more qualitative work in this field is necessary (Rowley et al., 2014).

\section{Summary of Literature Review Findings}

This study seeks to bring attention to existing counter narratives, which contradict the monolithic, dismal narrative being perpetuated throughout various forms of media concerning African American males. Through a qualitative case study approach, I seek to understand the experiences high-achieving African American males report as contributing factors to their academic success. The review of literature draws attention to the history of Black males and the effects of slavery on their current state of being, historical educational experiences, and school reform. Critical Race Theory and its 
application to African American males in the education system was highlighted to provide evidence of the effects of a pervasively racist system vexing students of color. The perceptions of educators, students, and parents were explored and lastly, counter narratives were underscored to provide context for my study.

Undoubtedly, African American males have a storied history in the United States, which must be considered when illuminating contributing factors to their success or failure. Also, Black males' perspectives must be considered as we determine how to make meaningful changes to the current state of reality for some of this population. Given this need, the focus of my research will be high achieving Black males and their perspectives on contributing factors to their success. Brooms (2016) suggested that "paying closer attention to how Black males perceive themselves academically may help inform us of opportunities to broaden their perspectives and enhance various characteristics for academic success-such as motivation and resilience" (p. 24). This need to give credence to how Black males perceive themselves academically situates my study in an opportune position to add to an area of research that is currently scarce. 


\section{CHAPTER THREE}

\section{METHODOLOGY}

The purpose of this study was to explore the perspectives of successful African American male high school students; specifically, what they identified as factors contributing to their success. This chapter includes a discussion and rationale of methodological features such as research design, context, sampling strategy, data collection, and data analysis. Justification of delimitations and limitations along with an explanation of processes for data verification are also found in this chapter. A key component of qualitative research is the researcher as an instrument of data collection; therefore, researcher positionality is provided. Lastly, ethical considerations specifying protections and rights of the participants are also incorporated into this chapter.

\section{Research Design}

To explore the perceptions of high achieving African American male high school students, a qualitative approach was employed. Qualitative research is an approach for exploring and understanding the meaning individuals or groups assign to phenomena (Creswell, 2014). In this case, the phenomenon being studied was successful African American males in the midst of the dismal, discouraging narrative being perpetuated throughout the United States school system and media. A qualitative approach was the most appropriate research design because student perspectives could be determined through the interview and observation process (Creswell, 2014). 
According to Merriam (1998), there are three basic forms of educational research; positivist, interpretive, and critical (Merriam, 1998). Within positivist forms of research, education is the object or phenomenon to be studied. Interpretive researchers consider education to be a process, with schooling being a lived experience. Meaning is therefore derived from understanding this process and subsets thereof. In critical research, education is viewed as a social institution designed for social and cultural reproduction and transformation (Merriam, 1998). Knowledge produced by this form of research is a critical examination of power, privilege, and oppression in areas of educational practice. The research design of this study incorporated critical research through the lens of Critical Race Theory.

\section{Phenomenology}

The qualitative design utilized was phenomenology. Phenomenologists have utilized this methodology to develop a deeper understanding of phenomena through the perceptions of the actors involved in the situation (Lester, 1999). Gathering deep information and perceptions through inductive, qualitative methods in order to represent a phenomena from the perspective of the research participant(s) is the essence of phenomenological studies. These studies focus on capturing rich descriptions of phenomena and their settings (Groenewald, 2004).

Phenomenology began as the German philosopher, Edmund Husserl sought to develop a new philosophical method to bring certainty to a civilization which was disintegrating at the time. While phenomenology also has its origins in the work of other philosophers, Husserl is considered to be the fountainhead of phenomenology in the twentieth century (Lester, 1999). According to Husserl (1970), pure phenomenological 
research seeks to essentially describe rather than explain and does not begin with hypotheses or preconceived notions. However, as this methodology has evolved, more recent researchers refute the possibility of starting without preconceptions or bias (Hammersley, 2000; Lester, 1999). These researchers argue that it is necessary to put emphasis on having clear interpretations and meanings that may be placed on findings while also making the researcher an interested and subjective actor as opposed to a detached and impartial observer (Plummer, 1983; Stanley \& Wise, 1993).

Phenomenology is an effective method to highlight the experiences and perceptions of individuals based on their own lived experience and therefore has the ability to challenge assumptions while informing and supporting policy and action (Lester, 1999).

According to the Mishara (1997), the field of phenomenology has evolved into multiple forms encompassing seven unique perspectives. These seven factions are descriptive phenomenology, naturalistic or constitutive phenomenology, existential phenomenology, generative historicist phenomenology, genetic phenomenology, hermeneutic (interpretive) phenomenology, and realistic phenomenology. The form of phenomenology I will be using is hermeneutic phenomenology which is concerned with the interpretation of the structures of experience and with how things are understood by people who live through these experiences (Wojnar \& Swanson, 2007). To come to an understanding of the human experience, hermeneutic phenomenology goes beyond basic knowledge of core concepts. This is exemplified in Heidegger's (1962) introduction of the concept of dasein, which is the human way of being in the world. The human inability to abstract themselves from various contexts that influence their choices and give meaning to their lived experiences is the meaning of dasein. Hermeneutic 
phenomenology, therefore, attempts to address the position of a person's dasein in relation to the broader social, political, and cultural contexts (Wojnar \& Swanson, 2007).

Phenomenological approaches can be applied to both single cases as well as multiple participant studies. Also, a multitude of methods can be used in phenomenological research such as interviews, observations, focus groups, and analysis of text. A general principal involved with this form of research is minimum structure and maximum depth of methods (Lester, 1999). The ability to make inferences based on the participant's experience increases precipitously when factors begin to recur among participants. However, a distinction must be made between this ability to make inferences and statistical validity. Phenomenological research can be robust in highlighting the presence of factors and their subsequent effects for individual cases, but must also be cautious about generalizing these findings to the population from which the information was drawn (Lester, 1999). This methodology is not intended to create generalizable knowledge, rather it is meant to bring understanding to a particular phenomenon.

\section{Context}

The participants in this study were students in a medium-sized urban school district in the southeastern United States. Approximately 42,000 students were enrolled in this district; with nearly 45 percent of students being students of color. Students participating in this study attended a high school referred to hereafter by the pseudonym Dorothy Height Academy (DHA) in the Champion Public School District (CPSD). This school provides an advanced and rigorous curriculum that meets common core standards through the lens of African-American history, culture, and culturally responsive teaching 
and learning strategies. A traditional college preparatory program launched in the fall of 2012, DHA serves at-promise males in grades 6-12, the majority of whom are AfricanAmerican.

The genesis of Dorothy Height Academy was a supplemental school program known as Black Males Working (BMW). BMW began as a community-based program focused on offering cultural and academic enrichment. The founder of BMW is a retired educator in the Champion School District who desired to offer cultural exposure and relevant content to African American males. After Black Males Working was in existence for two years, the superintendent of Champion School District noticed that academic and behavioral outcomes for students who participated in BMW were higher than the district norm for African American males. He then approached the founder of BMW to create a school patterned after the tenets of Black Males Working. Thus, the creation of Dorothy Height Academy while BMW simultaneously continues to thrive.

Dorothy Height Academy is a unique school in many ways. Students are required to adhere to the dress code which includes a navy-blue blazer with school crest, charcoal dress slacks, white button down shirt, and a purple tie. Another distinctive quality is that students are exposed to a variety of cultural and educational trips. These trips consist of college visits (almost always including a historically black college or university), international trips such as an excursion to Dubai, and historic landmark trips in which students explore places such as Washington D.C. Students also participate in community service during the school day and learn essential skills such as etiquette and public speaking through authentic experiences with boules, balls, and banquets. This unique program is based on high expectations for all scholars. As noted in the Scholar 
Handbook (2016), the "Well Principles" serve as a guide for student expectations. The following excerpt from the Scholar Handbook details these student expectations:

Well Behaved

Follow all school expectations \& district code of conduct

Well Mannered

Use manners when interacting with staff, scholars, families \& guests

Well Dressed

Be in appropriate dress code attire each day

Well Spoken

Speak fluently with confidence and composure

Well Read

Read nightly to increase vocabulary and enhance writing skills

Well-Traveled

Participate in cultural events, field trips \& trips abroad

Which leads to being...

Well Prepared for college, career and life

The handbook excerpt provides context of the unique experiences these students are exposed to at school on a daily basis. Through observations of this school environment and interviews with the participants, I hoped to gain a rich and detailed representation of the Dorothy Height Academy experience. The participant interviews are the primary source of data while the observations and document analysis provide context to these interviews.

\section{Participants}

Purposeful sampling was used to narrow the participants to a practical group. This form of sampling is based on the assumption that the investigator wants to gain insight or understand a phenomenon and must therefore select a sample from which the most can be learned (Merriam, 1998). This study included the graduating class of 2019. 
At the time of the study, they were juniors and will be the first group of students to fully matriculate from $6^{\text {th }}-12^{\text {th }}$ grade at Dorothy Height Academy upon graduation. With complete matriculation through this program, the impact on their achievement should be definitive. I also included students who were in the graduating class of 2019 but may not have matriculated at DHA since the sixth grade. Their perspectives can provide some dimension to the experience of attending such a school after having attended another school without the qualities of DHA.

There were 192 total students from grades 6-12 and 17 students in class of 2019. These students were all male. Among them, $62 \%$ of students qualified for free or reduced-price meals, and $8 \%$ qualified for special education services. Table 1 displays the disaggregation of enrollment by race.

Table 1

2016-2017 CPSD Dorothy Height Academy Enrollment by Race

\begin{tabular}{ccc}
\hline Race & Enrollment & $\%$ \\
\hline Black & 163 & 85 \\
Hispanic & 16 & 8 \\
Other & 10 & 5 \\
White & 2 & 1 \\
Total & 192 & 100 \\
\hline
\end{tabular}

Within the Class of 2019, selection criteria required participants to have at least 3.0 grade point average (GPA) on a 4.0 scale. At the time of the study, 15 students fit this criterion. An informed consent was sent to the guardians of the students who met the criteria. (See Appendix A for Informed Consent.) 


\section{Theoretical Framework}

Critical Race Theory is a critical examination of society and culture and the intersection of race, law, and power (Decuir \& Dixson, 2004). In 1994, Critical Race Theory (CRT) was used as an analytical framework to assess inequity in education. Educational studies grounded by Critical Race Theory should be guided by the following five principles:

1. Centralize race and racism and its intersections with other forms of oppression

2. Challenge dominant ideology

3. Represent a commitment to social justice

4. Value the lived experience of people of color, and

5. Use interdisciplinary perspectives, including education, sociology, and psychology (Kholi, 2008).

The work of Derrick Bell and Alan Freeman has been attributed to the start of the CRT movement (Bell, 1976; Delgado \& Stefancic, 2000; Freeman, 1978). Born out of the Critical Legal Series, Bell and Freeman were able to build on their frustration with the slow pace of improving race relations and eventually joined with Richard Delgado (1993) to solidify Critical Race Theory as a legitimate framework (Delgado \& Stefancic, 2000). Since then, scholars have used CRT as a framework to further analyze and critique educational research and practice (Decuir \& Dixson, 2004). CRT recognizes that racism is engrained in the very essence of the United States and consequently permeates its systems, policies, and institutions. 
The intersectionality element of Critical Race Theory is based on the idea that race is not the only factor that leads to the oppression and disempowerment of minorities (Delgado \& Stefancic, 2000). Intersectionality is defined as the examination of race, class, sex, national origin, and sexual orientation, and how their amalgamation manifests in various settings (Delgado \& Stefancic, 2000). This intersectionality component allows CRT to be a multi-dimensional framework and contributes to the focus on social justice within this theory. The overarching goal is to eliminate all forms of oppression through a focus on ending racial oppression and its contributing systems.

For the purpose of this study, a critical approach was applied through the examination of school systems, policies, and programming which contribute to the success of a typically maligned underrepresented group: African American males. The underlying assumption was that power, privilege, and oppression have led to the academic achievement gap; yet, some African American students are persevering and overcoming in spite of adverse educational practices. Within my study of high achieving African American males, Critical Race Theory was applicable because the manner in which African American males are perceived in the United States perpetuates substandard treatment across multiple settings. For example, there has been consistent underrepresentation of African Americans in Advanced Placement (AP) courses (Decuir \& Dixson, 2004). This underrepresentation has existed since the desegregation of American schools during the 1960's (Venzant Chambers, 2011). High-achieving students are often classified based on enrollment in Advanced Program courses. However, many African American students are not identified by their counselors and other school personnel for AP courses even when they meet requirements and have the 
proven ability to be successful (Decuir \& Dixson, 2004). Primary factors associated with the under-identification of African American students in AP programming include lack of teacher referral, poor test performance, and student choice. The combination of these issues all too often lead to the absence of African American males in gifted programs (Bonner, Lewis, Bowman-Perrott \& Hill-Jackson, 2009). This is an example of how racism is engrained in policies, systems, and programming which often lead to negative outcomes for African Americans.

This lack of identification makes sense when we examine the original intended purpose of $\mathrm{AP}$ at its inception. The initial rationale was to challenge and engage the highest-achieving students at the best US high schools (Schneider, 2009). This motivation was the foundation for teasing out the haves from the have nots, distinguishing the elite students to further their social mobility, and subsequently perpetuating the gaps which currently exist in American education. Many times, standardized test scores and educator recommendations are the only means for identification of the "haves". Test scores at best are an adequate measure for some but at the least are a poor measure for all (Bonner, 2003). Therefore, allowing a single test score to determine access to differentiated instruction is not advantageous for most students. If African American students are not perceived to be among the "highest achieving" or "elite students", then they are already operating at a disadvantage because opportunities to participate in programs like AP are often not promoted as an option. The implications for the subsequent academic achievement gaps and experience gaps will manifest for the duration of those students' lives. 
There is a substantial number of high achieving African American males in this country; however, their stories are largely untold (Bonner, Bowman-Perrott, HillJackson, James, \& Lewis, 2009; Harper \& Davis, 2012; Howard \& Associates, 2017). Critical Race Theory affords researchers the opportunity to counter deficit storytelling. I was compelled to attend to the perspectives of high achieving African American males in an effort to determine how their perspectives impact their own achievement; as opposed to allowing others to tell their story. My research has the capacity to serve as a catalyst for shifting the focus and changing the narrative of African American males; a purpose which is aligned to the tenets of Critical Race Theory. African American males are among the most marginalized and disenfranchised groups in this nation; therefore, research which dispels the myths of inevitable underachievement is imperative.

\section{Data Collection}

To conduct this research, I utilized multiple sources of data. Various sources of data provide a means of triangulation of the information; which subsequently provides legitimacy (Merriam, 1998). These include semi-structured interviews, observations, and document analysis. In what follows, I discuss the processes of data collection for each of these data sources.

\section{Semi-Structured Interviews}

Semi-structured interviews offer researchers the flexibility to ask open-ended questions that can be more flexibly worded (Merriam, 1998). When specific information is desired from participants, it is appropriate to ask highly structured questions.

However, the largest part of the semi-structured interview is guided by a list of questions or issues to be explored. This format allows the researcher to respond to the emerging 
worldview of the participant or to new ideas and concepts (Merriam, 1998). Semistructured interviewing allowed me to begin with a set of questions but also develop questions on an impromptu basis depending on dialogue and interactions with the participants. I conducted face-to-face, one-on-one interviews that served to centralize the voices of the participants. The majority of the interview questions were directly linked to one of the tenets of Critical Race Theory. Interviews were recorded and transcribed verbatim. (See Appendix B for Interview Protocol.)

\section{Observations}

Observations were conducted in classrooms and common areas within the school. Interactions between adults and students; visuals such as posters, banners, and quotes displayed; and general routines and procedures were observed. These observations helped to contextualize participant responses and provided an enriched perspective about the operation of the school. The observation protocol consisted of field notes in a journal (Creswell, 2014). These notes were organized to include demographic information such as date, time, and place of field setting; while also including both descriptive notes and reflective notes. Each page of the field journal was divided into two sections to distinguish between the descriptive and reflective notes.

\section{Document Analysis}

A number of documents relevant to Dorothy Height Academy were analyzed to bring context to the interviews. These documents helped to raise questions for interviews, support or challenge interview data, and provide thick description (Glesne, 2016). The student handbook, meeting notes, academic data analysis tools, and correspondence with parents were expected to be essential documents. These documents 
also served to provide context to the culture, climate, and priorities of the school. Also, visual data provided historical and contextual dimensions to observations and interviews to enrich what was seen and supported (Glesne, 2016).

\section{Data Analysis}

The analysis of phenomenological data can be a messy process because there is often a large quantity of data such as interview notes, tape recordings, and field notes from observations. The data doesn't necessarily fall into neat categories and there can be many possibilities of ways to interpret the findings (Lester, 1999). Some researchers within the field of phenomenology avoid the terms 'data analysis' and instead refer to this concept of explicitation of the data (Groenewald, 2004). Whereas 'data analysis' implies breaking data into parts and could require a segmented view of the phenomena, explicitation involves investigation of the constituents of the phenomena while keeping the context whole (Groenewald, 2004). This concept was also described by Keen (1975) as he states, “...unlike other methodologies, phenomenology cannot be reduced to a 'cookbook' set of instructions. It is more an approach, an attitude, an investigative posture with a certain set of goals." There was therefore a reluctance by many researchers to focus too much on the specific steps, however five main components of explicitation were agreed upon (Groenewald, 2004). The explicitation process consists of bracketing and phenomenological reduction; delineating units of meaning; clustering of units of meaning to form themes; summarizing each interview; and extracting general and unique themes from all the interviews to make a composite summary (Groenewald, 2004). 
Consistently reflecting on the data, organizing them, and attempting to uncover the themes which have emerged are basic components of data analysis in qualitative studies, making them relevant and profound (Glesne, 2016). Therefore, data analysis for this study occurred through transcription, coding, analyzing, and thematic inquiry (Miles, Huberman, \& Saldana, 2014). To analyze the interviews, deductive and inductive coding was utilized. The initial coding was descriptive, then evolved as new themes emerged and codes were be modified or removed from the study as needed. This was determined by the relevance and frequency of codes. Given the unique context of the school, I expected to observe themes around familial influence, the culture of school, the experiences offered through the school, and relationships cultivated through the school.

Coding was be influenced by the research question and Critical Race Theory framework. A CRT framework challenges dominant ideology that supports deficit theorizing (Solorzano \& Yosso, 2002) therefore I expected to find themes associated with the prevalence of deficit thinking on behalf of educators prior to attending Dorothy Height Academy. I also anticipated a theme associated with the impact of race and racism on the participants' life experience in general and educational experience specifically. Lastly, A CRT analysis interrogates the unquestioned use of a White, male majority experience as use for a standard by which people of color are measured (Iverson, 2007); consequently, I was attentive to themes connected to the implications of dominant culture on the participants' lives. Employing a CRT analysis also helped to explore ways in which culturally relevant programming has (or has not) assisted in the successful matriculation through school. The interview protocol (see Appendix B) provided open-ended questions in an effort to generate meaningful responses from the 
participants. This protocol also reflected the Critical Race Theory lens as it offered questions to stimulate dialogue around the tenets of CRT. Specifically, the two tenets (a) challenging dominant ideology and (b) valuing the lived experience of people of color were persistent throughout the interview protocol. As the interviews were semistructured, the goal was to trigger thoughts and subsequent responses that contributed to countering the dominant narrative around the lived experience of people of color.

\section{Qualitative Validity}

Reliability and validity in this form of qualitative research are often referred to as trustworthiness which comprises the following four aspects: credibility, transferability, dependability, and confirmability (Morse, Barrett, Magan, Olson, \& Spiers, 2002). Internal validity, construct validity, and external validity all play a key role in creating rigorous phenomenological studies. Merriam (1998) argues that the observer's critical presence in the midst of the occurrence of phenomena, observation, and triangulation of participants' perspectives allows for case studies to qualify as both scientific and trustworthy. This study upheld the standards of validity in a qualitative study because as the researcher and primary instrument of data collection, I was able to make interpretations of reality directly through interviews, observations, and document analysis (Merriam, 1998). Data analysis also contributed to greater trustworthiness as I was able to triangulate the data with multiple data sources. Through the use of direct quotes from participants, context and clarity was provided which resulted in the rich, thick descriptions characteristic of qualitative studies (Creswell, 2009). This is viewed as a definite strength of qualitative research and it is important to be able to understand the 
perspectives of the participants given their context and present a holistic interpretation of what is occurring (Merriam, 1998).

\section{Credibility}

Triangulation, member checks, and repeated observation enhanced the credibility of this study (Glesne, 2016). In qualitative research, triangulation is more about gaining a holistic understanding than being a technological solution for ensuring validity (Merriam, 1998). In this regard, triangulation, or a holistic understanding, was gained through the use of three data collection methods: interviews, observations, and document analysis. The interviews were audio recorded and transcribed to produce verbatim interview transcripts. Member checks occurred by taking the data and tentative interpretations back to the participants to ask if the results are plausible. We discussed the questions I asked, their responses, and any paraphrases I may have made. The participants also clarified any words that were inaudible during transcription to ensure clarity of meaning. Observations occurred during two separate visits to increase validity of the findings.

\section{Transferability}

Transferability refers to the degree to which the results of qualitative research can be generalized or transferred to other contexts or settings (Merriam, 1998). By explicitly communicating descriptive information such as number of participants, location, data collection methods, and data analysis techniques, another researcher would be able to follow the process used during this study. Qualitative research is not meant to be generalized across settings, however, readers of my research should be able to envision how the findings of my study would transfer to other similar school settings. These 
findings are aimed to inform pedagogy and to assist educational practitioners in their future work.

\section{Confirmability}

Confirmability refers to the degree to which the results can be confirmed or corroborated by others. The assumption is that each researcher brings a unique perspective to the study (Shenton, 2004). The use of triangulation helped to mitigate the influence of researcher perspective and promotes confirmability.

\section{Dependability}

In-depth coverage of practices ile conducting the research allows the reader to assess the extent to which proper research practices have been followed (Shenton, 2004). An electronic database including notes, documents, or other relevant information was used to ensure dependability of the study. The reliability of the study hinged on the dependability of this data.

\section{Researcher Positionality}

As an administrator in a large, urban, school district struggling to educate African American males effectively, I have always been perplexed by the focus on the evergrowing achievement gap between White students and their counterparts. As a mother of three flourishing African American males, a wife to one successful African American male, a daughter of a positive African American male, a sister-in-law to a productive African American male, and an aunt to two thriving African American males, my view of the accomplishments, potential, and capabilities of the African American male contradicts the narrative portrayed so prevalently. To embrace the notion that African American males are somehow predestined, biologically or otherwise, to achieve less than 
their White peers is to succumb to a deficit mindset perpetuating failure every day in schools. I refuse. My greatest sensibilities indicate such factors as environment, relationships, inclusive systems, and culturally-responsive pedagogy have a vast effect on the achievement of any student; and most notably those who are disenfranchised. Therefore, this study was my quest to identify the factors which contribute to the achievement of African American males by listening to the voices of successful African American males. Milner (2007) suggests that researchers should possess or pursue deeper racial and cultural knowledge about themselves and the community or the people they are studying. This process of racial and cultural consciousness as research is conducted affirms the tenets of Critical Race Theory and is the basis of my research. An example of a school endeavoring to accomplish groundbreaking work with African American males is only an hour away from Louisville, Kentucky; so I felt an obligation to take advantage of the opportunity to give voice to their stories in an effort to form a more comprehensive narrative around the achievement of African American males. The importance of the narrative, counter-narrative, and naming of one's own reality in education are essential precepts of Critical Race Theory (Milner, 2007). Further examination of positionality will be included in detail in an appendix (See Appendix C).

\section{Ethical Considerations}

This study required the approval of the Institutional Review Boards (IRB) of the University of Louisville and Champion School District. IRBs use five basic guidelines drawn from the principles of respect, beneficence, and justice to inform their decisions when reviewing research proposals (Glesne, 2016). The guidelines state that research subjects must have sufficient information to make informed decisions about participating 
in the study; must be able to withdraw from a study without penalty; unnecessary risks must be eliminated; benefits must outweigh the risks; and only qualified investigators should conduct experiments (Glesne, 2016).

For my study, informed and voluntary consent was acquired for every participant of the study. Full disclosure of the purpose, intent, and use of the study was given to the participants and their guardians, who granted permission for the students due to the participants being under the age of consent. I also followed applicable code of ethics necessary in order to conduct my research in a manner which did no harm and was open and honest. I member-checked the interview data as soon as it was possible while also protecting and preserving my records through a secure database.

I had access to students at Dorothy Height Academy because I have familial connections with the principal and the founder of the school. I also have a nephew in the class of 2019. He is excluded from the sample in an effort to ensure bias is not a factor. I was also careful to adhere to all guidelines for interview scheduling and access to students. I did not share any preliminary information with anyone, all results were made available at the same time for all interested parties.

\section{Summary of Methodology}

A qualitative approach was employed as I conducted research through a Critical Race Theory lens to determine what high achieving African American males identify as contributing factors to their success. I conducted a phenomenological study of the Dorothy Height Academy by interviewing students of the class of 2019 who have at least a 3.0 grade point average. In addition to interviews, observations and document analysis occurred. Both deductive and inductive coding were utilized to determine thematic 
trends. I am hopeful that this research can bring volume to the voices of students who are often overlooked and undervalued.

African American males across the United States deserve an opportunity to learn in a manner that is conducive to their needs. Every student does. There are many African American males who are high achieving academically, so what are the factors contributing to these students' success? This research focused on finding these contributing factors to to ensure equitable education for all students through qualitative analysis of current practices. We can tell this story in a manner which facilitates replication of the experiences students hold valuable and consequently rewrite the narrative of African American males. 


\section{CHAPTER FOUR}

\section{RESEARCH FINDINGS}

The purpose of this study was to amass perspectives of high achieving Black males concerning contributing factors to their success. These participants attend school in a unique setting; an all-male, predominantly Black college preparatory academy and have earned a cumulative grade point average (GPA) of 3.0 or higher. Their lived experience as a student at this school and subsequent goals, perspectives, and opinions were examined to determine their overall assessment of the contributing factors of their success. Critical Race Theory was used as a theoretical framework for this study, as it provides researchers the opportunity to counter deficit storytelling (Solorzano \& Yosso, 2002). The importance of the narrative, counter-narrative, and naming of one's own reality in education are essential precepts of Critical Race Theory (Milner, 2007). Counter narratives were expected to emerge from the participants as they named their own reality in opposition to the current negative and demeaning classification often associated with Black males (Iverson, 2007). The phenomenological methodology served as a means of gaining insight into the lived experiences of these participants (Lester, 1999). An assets-based approached was used to analyze the data as opposed to deficit-based approach.

The study was conducted in Champion School District at Dorothy Height Academy and consisted of 15 participants from the class of 2019 who have earned a 3.0 grade point average or above. Each student participated in a semi-structured interview 
and a follow up conversation for member checking. The participants in the study were chosen because they are members of the class of 2019, the first class to have the opportunity to fully matriculate through the school from sixth to twelfth grade. The 3.0 GPA was selected as an indicator of high academic achievement because it is greater than the average GPA of 2.79 for high school students in the United States in core subjects; also higher than the average GPA of 2.9 for high school males; and lastly, 3.0 is also greater than the 2.69 average GPA of Black high school males (National Center of Education Statistics, 2018).

To give full perspective of the participants in this study, the next section of this chapter will provide profiles for each participant that include a brief introduction to the participants' general family background, grade point average, and future aspirations. Following introductions, overarching themes that were found throughout the study are highlighted and expanded upon.

Note: Participant profiles may reference an extra-curricular activity called Black Males Working (BMW). This program was the genesis of Dorothy Height Academy. BMW began as a community-based program focused on offering cultural and academic enrichment. The founder of BMW is a retired educator in the Champion School District who desired to offer cultural exposure and relevant content to African American males. After Black Males Working was in existence for two years, the superintendent of Champion School District noticed that academic and behavioral outcomes for students who participated in BMW were higher than the district norm for African American 
males. He then approached the founder of BMW to create a school patterned after the tenets of Black Males Working. Thus, the creation of Dorothy Height Academy.

\section{Participant Profiles}

$\underline{\text { Alex }^{3}}$

Alex resides in a household with his parents and his grandmother. His grandmother has a great deal of influence in his educational motivation. Alex's parents are high school graduates who did not pursue post-secondary education. At the time of data collection, Alex has a 3.75 grade point average and likes to play sports and hang with friends in his free time. He is active in the school community participating in Beta Club, Student Government Association, and the Black Male Working program. He would like to attend college and major in Mechanical Engineering with a possible double major in Business Management.

$\underline{\text { Andre }}$

Andre lives with his uncle due to the passing of his mother when he was in sixth grade. He feels a very strong connection to the staff and students of Dorothy Height Academy due to the support he received and continues to receive after the passing of his mother. Prior to attending this school, he was a truant student with low grades. Most of the people in his family have not attended college. Before his mother's passing, he made a promise to her along with the principal of Dorothy Height Academy that he would become something special. He told his mother he would not waste his life. He avowed, "I'm doing it for her." His grade point average at the time of data collection was a 3.0.

He is active in his church, plays on the varsity football team, and participates in the Black

\footnotetext{
${ }^{3}$ Pseudonyms are used for participant and school staff names.
} 
Male Working program. Andre aspires to become a chief firefighter, so that he could give back to his community, and that his work would be impactful.

$\underline{\text { Dominick }}$

Dominick comes from a two-parent home and his parents are extremely engaged in his school life. His cumulative grade point average at the time of data collection is a 3.2. He enjoys listening to music and creating art. Dominick is actively involved in the Global Engagement Leadership class which allows him to serve as a school ambassador. He also participates in the Black Male Working program. Dominick plans to go to college possibly majoring in Criminal Justice or Entrepreneurship.

\section{$\underline{\text { Donovan }}$}

Donovan is the son of a college professor. Both of his parents are in the home and extremely active in his education. Donovan has a cumulative grade point average of 3.4 at the time of data collection and interns with a local university through a partnership with Dorothy Height Academy. He is active in his church and participates in the Black Male Working program. Donovan plans to attend a Historically Black College or University (HBCU) after graduation.

$\underline{\text { Elijah }}$

Elijah is the son of a single mother. He is aware of siblings he has on his father's side of the family but does not have a relationship with them nor his father. His mother put him at Dorothy Height Academy to give him an opportunity to actually graduate high school, unlike many of their family members. Elijah participates with Black Males Working program and has a 3.0 grade point average at the time of data collection. He plays football, runs track, and wants to begin wrestling. Elijah's dream is to play in the 
NFL but he also plans to go to college to be a computer programmer and video game designer.

$\underline{\text { Isaiah }}$

Isaiah comes from a two-parent home where his mother is a teacher. She has a Master's degree and both parents are very active in his education. His cumulative grade point average is 3.0 at the time of data collection and he plays football. Isaiah has his preferred colleges narrowed down to three schools; one of which is an out-of-state option and the other two are in-state universities. He plans to major in civil engineering.

Jaxon

Jaxon's grandmother serves as his primary guardian. She ensures he does well academically and keeps him involved in his extracurricular activities. His cumulative grade point average is 3.6 at the time of data collection and he participates in the Black Males Working program. Jaxon is also an intern at a local research facility through a partnership with Dorothy Height Academy. He recently completed a research project with a neighboring university that focused on phenolic compounds for preserving fruits and vegetable shelf lives. Jaxon wants to major in biomedical engineering in college and he enjoys playing basketball and football.

\section{$\underline{\text { Jeremiah }}$}

Jeremiah lives with both of his parents. Each of his parents hold a Master's degree and are actively involved in his education. Jeremiah says that his father always tells him he should be better than him. His grade point average is 3.7 at the time of data collection and he participates in football, Beta club, Student Government Association, 
and the Black Males Working program. He plans to major in electrical engineering and his favorite subjects are math and science.

$\underline{\text { Jordan }}$

Jordan is from a two-parent home. His parents both have college degrees and are very engaged in his education. His cumulative grade point average is 3.9 at the time of data collection and he participates in the Black Males Working program. Jordan has been active in his church since a young age and aspires to play baseball and/or football for a Division I university. Jordan plans to major in Criminal Justice and enjoys playing video games in his free time; which is limited due to his intense athletic schedule.

$\underline{\text { Joshua }}$

Joshua lives with both parents who are both college graduates. He has 13 years of Montessori schooling but when his father read about Dorothy Height Academy in the local newspaper, he decided this school would be best for Joshua. He began DHA in $7^{\text {th }}$ Grade and has a grade point average of 3.6 at the time of data collection. He participates in the Black Males Working program. He also volunteers for his parents' non-profit organization, African American Forum, while also being actively engaged in his church. Joshua aspires to go into public broadcasting or journalism.

$\underline{\text { Keon }}$

Keon has attended Dorothy Height Academy since the sixth grade. He lives with his mother who is very involved in his education. Keon has a 3.3 grade point average at the time of data collection and he is actively involved in track, Student Government Association, and the Black Males Working program. He would like to become a financial advisor or work within the business sector after college. 
$\underline{\text { Mason }}$

Mason is the middle child of his parents' three sons. His parents do not allow any grade below a B in their house and Mason characterizes them as strict. They also reward him when he accomplishes his goals, however. At the time of data collection, his cumulative grade point average is 3.8. Mason is actively involved in his church, plays both football and baseball, is a Beta Club member, and a participant of the Black Males Working program.

$\underline{\text { Noah }}$

Noah is the son of a single mother. He came to Dorothy Height Academy as a freshman because his mother wanted to improve the trajectory of his educational future. Noah has a 3.3 cumulative grade point average at the time of data collection and reports that he strives to give his best in every class. He plans to attend college but is unsure what he will major in. Noah plays basketball and enjoys the deep connection he has with his classmates.

$\underline{\text { Thad }}$

Thad is raised by his grandmother and great grandmother, who are both actively involved in his education. He describes the males in his family as either dead or not active in his life. He reports that attending Dorothy Height Academy has helped him see how to be a man and specifically, how to be a Black male in society. Thad has a 3.8 cumulative grade point average at the time of data collection and is actively involved in National Honor Society for Spanish. He is an active member of his church and participates in a program called Going Pro that helps him become college ready. When his schedule permits, he participates in the Black Male Working program and he enjoys 
debating topics that people often feel one-sided about. He would like to study law, criminal justice, or political science in college.

\section{$\underline{\text { Xavier }}$}

Xavier refers to his parents as "law enforcement" because he perceives them to be highly strict. His grade point average is 3.0 at the time of data collection and he participates in the Black Males Working program, Future Farmers of America, Student Technology Leadership Project, soccer, and baseball. Xavier has many goals and aspirations. He would like to go to college on an athletic scholarship playing baseball and soccer. He plans to major in journalism but would also like to join the Air Force. After undergrad, Xavier would love to play Major League Baseball or Soccer, then go to veterinarian school.

The following summary table displays the participants along with their grade point average at the time of data collection, the year they began at Dorothy Height Academy, their home experience, and the number of extra-curricular activities in which they participate. This information provides a picture of each student's academic achievement in conjunction with the length of time in attendance at an all-male, college preparatory academy. The table is also meant to give perspective on the background of their home life and how many activities they are able to balance with academics. 
Table 2

Participant Profiles

\begin{tabular}{ccccc}
\hline Participant & $\begin{array}{c}\text { Cumulative } \\
\text { Grade Point } \\
\text { Average }\end{array}$ & $\begin{array}{c}\text { Year } \\
\text { Started at } \\
\text { DHA }\end{array}$ & $\begin{array}{c}\text { Home } \\
\text { Environment }\end{array}$ & $\begin{array}{c}\text { No. of } \\
\text { Extra- } \\
\text { Curricular } \\
\text { Activities }\end{array}$ \\
\hline Alex & 3.8 & $6^{\text {th }}$ Grade & Two-Parent & 3 \\
Andre & 3.0 & $6^{\text {th }}$ Grade & Guardian & 3 \\
Dominick & 3.2 & $6^{\text {th }}$ Grade & Two-Parent & 3 \\
Donovan & 3.4 & $6^{\text {th }}$ Grade & Two-Parent & 2 \\
Elijah & 3.0 & $8^{\text {th }}$ Grade & Single-Parent & 3 \\
Isaiah & 3.0 & $10^{\text {th }}$ Grade & Two-Parent & 1 \\
Jaxon & 3.6 & $8^{\text {th }}$ Grade & Guardian & 3 \\
Jeremiah & 3.7 & $6^{\text {th }}$ Grade & Two-Parent & 4 \\
Jordan & 3.9 & $6^{\text {th }}$ Grade & Two-Parent & 4 \\
Joshua & 3.6 & $7^{\text {th }}$ Grade & Two-Parent & 3 \\
Keon & 3.3 & $6^{\text {th }}$ Grade & Single-Parent & 3 \\
Mason & 3.8 & $6^{\text {th }}$ Grade & Two-Parent & 5 \\
Noah & 3.3 & $9^{\text {th }}$ Grade & Single-Parent & 1 \\
Thad & 3.8 & $6^{\text {th }}$ Grade & Guardian & 4 \\
Xavier & 3.0 & $6^{\text {th }}$ Grade & Two-Parent & 5 \\
\hline
\end{tabular}

\section{Themes}

Consistently reflecting on the data, organizing them, and attempting to uncover the themes which have emerged makes a study more relevant and profound (Glesne, 2016). Therefore, the data were analyzed through transcription, coding, and thematic inquiry (Miles, Huberman, \& Saldana, 2014). Deductive and inductive coding were utilized to analyze the interviews. The initial coding was descriptive, but, evolved as new themes emerged. I expected to observe themes around familial influence, the culture of school, the experiences offered through the school, and relationships cultivated through the school.

Coding was also influenced by the Critical Race Theory (CRT) framework. The CRT framework challenges dominant ideology that supports deficit theorizing (Solorzano 
\& Yosso, 2002) therefore I expected to find themes associated with the prevalence of deficit thinking on behalf of educators prior to attending Dorothy Height Academy. I also anticipated a theme associated with the impact of race and racism on the participants' life experience in general and educational experience specifically. Lastly, CRT analysis interrogates the unquestioned use of a White, male majority experience as use for a standard by which people of color are measured (Iverson, 2007); consequently, I was attentive to themes connected to the implications of dominant culture on the participants' lives. Employing a CRT analysis also helped to explore ways in which culturally relevant programming has contributed to the success of participants.

The overarching themes identified in the interviews, observations, and document analysis of the participants from Dorothy Height Academy are reported in four categories to provide adequate acknowledgement of participant voices. Themes concerning the manner in which participants (1) Defining Success; (2) their School Experiences; (3) who they define as Influencers; and (4) their Resulting Personal Beliefs, Values, and Perceptions are conveyed in an effort to answer the following research question: What experiences do high-achieving African American male high school students report as contributing factors to their academic success?

\section{Defining Success}

Critical Race Theory affirms the experiences of people of color instead of assuming the majoritarian viewpoint to be fact. In so doing, interview questions yielded responses seeking to determine how the participants defined success instead of assuming the majoritarian perspective to be valid. When asked to define success, the participants overwhelmingly indicated the notion that it was "more than grades." While participants 
acknowledged that grades were a definite part of success, they also identified resiliency, helping others, giving their best effort, and gaining knowledge as evidence of success. The participants corroborated and substantiated these perceptions of success repeatedly. When asked to define success Andre said, "Success is being open to overcome trials and tribulations because everyone has to overcome some kind of obstacle throughout their life no matter what the topic is. School is going to get tough, so you just have to be able to bounce back if something happens." His classmate Donovan also referred to this need as he stated, "give your best effort rather than throwing in the towel when it doesn't work for you. Prove to yourself you can get through it and achieve." This reference to the need for resiliency in order to obtain success is not necessarily the traditional or majoritarian definition of success, but for many Black males, they recognize this need out of an abundance of opportunities to demonstrate their own resilience throughout their schooling. Another participant, Keon, spoke about resiliency when defining success also when he stated, "Success is learning and overcoming different obstacles." Whether it be due to an ill-fitting curriculum, culturally incompetent educators, an antiquated school system, or simply the plight of Black males in the United States, resiliency is necessary to gain success no matter their environment.

Another aspect of success that multiple participants emphasized was the need to help others around you in order to be successful. This focus on communal learning or collective accomplishments authenticates the seminal research of Hale-Benson (1982) where she stated that African American children engage in people-oriented learning styles and therefore preferred to work collaboratively in groups with others. For six out of 15 participants of this study of high achieving Black males, their preference for 
working collaboratively is bolstered by their genuine concern for others. Both Alex and Elijah discussed helping others as they defined success. Elijah stated, "I define success by just trying to influence all your friends around you, being a good role model..." These scholars' definition of success encompasses helping others just as a line in their school creed signifies, "I represent my family, even my community as a whole and I refuse to let negativity keep me from my goal." It is possible that the tenets of the school in which they attend heavily influenced their definitions of success.

Another key feature of success as described by the participants is giving their best effort. Dominick explained, "Success in school is basically being able to put forth your best effort all around. So not only in the classroom, but being able to be an academic scholar, a brother to everyone else here at school." There seemed to be a common understanding that their best effort was good enough and improving one's self was the goal. Noah detailed this concept as he stated, "Improving yourself and achieving that the best way possible, even if it isn't pulling all As, just giving your best is success." All of the participants acknowledged a level of hard work and dedication that is necessary in order to attain true success. They believed their efforts would reap great benefit.

Six participants discussed gaining knowledge as they outlined their definition of success. Jordan discussed being teachable and likable in order to get the most out of your classes. Mason offered information about getting knowledge both in and out of the classroom. While the participants were definitely speaking of academic knowledge, they also brought attention to gaining knowledge through experiences and the value of such. They have been on cultural trips to Dubai and South Africa; which are definitely more valued avenues of gaining knowledge for the participants. These trips bring perspective 
to their own self-identity and offer exposure to the world outside of their norm. Xavier emphasized the influence such experiences as he explained, "These opportunities impacted my tremendously education-wise because I am able to study different things I never thought I would be able to at my age." Having the opportunity to visit South Africa and tour Nelson Mandela's former jail cell exemplifies the pinnacle of culturally relevant pedagogy. The participants understand the benefit of such an experience as evidenced by their collective agreement that they would not be as successful had they not attended Dorothy Height Academy. Every participant expressed this sentiment.

When analyzing the participant's responses concerning their definition of success, I noticed that much of what they discussed was reflected in the school's motto or creed. Through document analysis of the Scholar Handbook (2018), I noticed the school's motto is Raising Our Young men to Achieve and Leading them to Succeed. The emphasized letters spell out the school's mascot: the Royals. The school creed is as follows:

I promise to give my very best to achieve my every goal.

To be disciplined with everything in my control.

Learning as much as I can for knowledge is the key

There is nothing I cannot do, but the first step starts with me.

I represent my family, even my community as whole and I

Refuse to let negativity keep me from my goal.

I will exceed and excel if I just have faith and believe

I am a Dorothy Height Academy Royal

And there is no limit to what I can achieve!

I will rise above all prejudices 
And stay positive the whole way through.

For I am a Dorothy Height Academy Royal

And you can be one too!

Both the school motto and scholar creed offer ideals that participants echoed in their definition of success. These ideals were further corroborated during both of the on-site observations I conducted as I observed students exhibiting these very characteristics. Specifically, I observed students who were hard at work, disciplined, and focused. The participants have cultivated their own ideals of success based, at least in part, on their lived experiences at Dorothy Height Academy.

\section{School Experiences}

The participants in this study share a very unique school experience and this experience was a distinct theme throughout the interviews. As detailed previously, the school is an all-male, majority African American, college preparatory academy that provides a rigorous and advanced curriculum through the lens of African American history. Birthed out of a successful Saturday morning enrichment program known as Black Males Working, the school seeks to eliminate achievement gaps and effect change for the district's most disenfranchised population of students. The school offers partnerships and internships with multiple universities and businesses and there is a distinct culture of high expectations for all students. The Well Principles, as detailed in Chapter Three, include scholars being well-read, well-spoken, and well-prepared. To bolster and support these academic expectations, scholars have access to individual tutoring with teachers and tutoring through the Black Males Working Program twice a week. Also, through the Black Males Working Program, scholars have the opportunity to 
participate in seminars, college visits, symposiums, national and international cultural trips. One could imagine that through these experiences, there is a school culture that effects these scholars immensely. When describing their lived experience at Dorothy Height Academy, scholars prodigiously shared thoughts on aspects of their school experience such as brotherhood, the supportiveness of the staff, and assistance with future goals through academic achievement.

Based on interview responses and observation field notes, attending school with the same group of males from sixth to twelfth grade has helped to cultivate a strong brotherhood among the participants of this study. This brotherhood is one that signifies an undeniable bond built through common interests, goals, and experiences. Participants noted supporting each other and motivating one another as characteristics of their brotherhood. Even for the students who did not begin in sixth grade, they felt the effects of brotherhood and became acclimated to it. Donovan, a participant who has attending Dorothy Height Academy since the sixth grade said, "We had a brotherhood kind of spring up almost immediately. We had a chemistry unlike other schools, and this helped us progress as students. I wanted to stay here because of the brotherhood." Thad also spoke about brotherhood but this experience was important to him for different reasons. He illustrated how brotherhood helped him when he said:

The brotherhood experience is something that I never really had growing up because I grew up in a predominantly female house. Every male in the house is either dead or just doesn't live with us. So being in this school has pretty much really helped me see how to be a man. How to walk like a man and talk like a man and just be a Black male in society. 
Every participant interviewed discussed the power of brotherhood within the school. Dominick also shared about brotherhood as he stated, "Being able to be at school with people who look like me and who have the same mindset as me makes things easier versus going to a regular high school. We can relate to each other on personal levels." All the participants discussed perceptions about the bonds of brotherhood, shared experiences, and the resulting benefits therein.

Another element of the school experience that every participant expressed is the supportive staff and environment. They detailed how the staff motivated and compelled every scholar and genuinely cared about them. When discussing what made Xavier stay at this school, he spoke about the staff at Dorothy Height Academy in comparison to that of a traditional high school. He shared, "They treat me like I'm an actual person, rather than if I were at a regular high school, then I would be just another Black boy from the hood to them." Xavier expounded upon this comparison by detailing the access and availability of academic support at Dorothy Height Academy. "We have BMW on Saturdays, which also helps with homework and offers lifestyle skills. We have all these opportunities that a regular high school student probably couldn't get for free.” In agreeing with this notion, Dominick stated, "Staff and administration are basically the reason for everyone's success. If you don't have someone pushing you, then how do you expect to bring the best out of them? So that's what the staff and administration does for us." Participants spoke positively about the supportive staff and environment that affected them daily; especially highlighting tutoring opportunities, access to teachers, and the option to reassess if they performed poorly on an assignment. These points of evidence suggest an environment that exhibits the characteristics of a growth mindset and 
motivates students to perform at their optimal potential. Participants described teachers who are available at any time to answer questions, even if by text or phone call. Joshua quipped, "Teachers here are way different than teachers at any other school. You can never find a teacher that will FaceTime you and help you with your homework anywhere else." Scholars at Dorothy Height Academy have a supportive staff that have created an environment that facilitates students rising to their highest capabilities and provides the supports necessary to attain success, by any means necessary.

Participants describe academic achievement as a non-negotiable part of the school experience at Dorothy Height Academy. The school embodies a culture of high expectations and the scholars rise to the expectation as evidenced by both interactions I observed and school assessment data. One participant described the rationale behind such high expectations when he noted,

What they teach you here is that since we as African American males undergo a struggle that is usually exclusive to us, we have to push more and there is no room to not meet the expectation. This school teaches us to exceed expectations that others have for you and then set your own expectations.

This mindset allows scholars to take an underdog approach to their achievement and motivates them beyond the status quo. Academic achievement is also viewed as a means to an end, the gateway to the scholars' future aspirations. Consequently, the administration of Dorothy Height Academy expose scholars to the myriad possibilities that lie ahead of them. There are opportunities for internships in their desired future career pathways that support their employment goals. For example, Jaxon would like to major in biomedical engineering in college so he currently interns at an engineering 
facility where he completed a research project on phenolic compounds for preserving fruits and vegetables shelf life. A partnership with Dorothy Height Academy and a local university made this internship possible. The partnership allows students to get experience and explore their interests to help them work towards their future aspirations. Scholars also have opportunities for college preparation through ACT and SAT workshops, dual-credit classes, and college tours. Thad discussed how such opportunities have a powerful impact on his academic success and stated, "I've had many college visits and then those colleges send me mail about the visit. I also have many scholarship opportunities so going to colleges, touring them and getting a feel of what college life would be like helps me strive more for that." There is an evident college preparatory environment at Dorothy Height Academy and this helps their scholars to not visualize their future but make plans to actualize their goals.

The participants of this study share an exceptional school experience as evidenced by the high expectations, internship opportunities, and cultural trips. Every participant identifies this experience as a defining component of his academic success. The (2018) Scholar Handbook details these expectations and guidelines explicitly. However, in order to bring these elements of the Dorothy Height Academy experience to fruition, it requires many key players to engage with scholars in a manner that fosters brotherhood, a supportive environment, and motivates scholars to accomplish their future aspirations. Observation field notes detail the level of support displayed between the scholars. For example, an instance between an administrator and a student is noted in the field notes. The student was visibly upset due to a disciplinary action taken by a teacher. He appeared to dread the consequences as he reported to the administrator's office. Before 
entering the office, the administrator pulled the student to the side, told him to go into the restroom and fix himself, and then emerge more composed. The student did so and when he came out of the restroom, the administrator asked the student if he was well-prepared for the conversation they would have. He replied affirmatively and they engaged in a calm conversation in the administrator's office. This interaction was noted as respectful and it preserved the dignity of the student while also holding him accountable. The interaction also provided a glimpse of the supportive environment the participants spoke about. These key players in this supportive environment are essential influencers of the participants. These influencers are detailed in the following section.

\section{Influencers}

As the participants of this study spoke about defining success and their school experiences, they always included people within the school who have had great influence on their mindset, goals, and progress towards such. The impact these great influencers have on the participants was evident as each participant spoke about particular individuals within the school who have helped them in various ways. Every participant identified school administrators, teachers, and parents as influencers.

When detailing the school experiences of the participants, participants highlighted teachers in general, due to their willingness to help students through tutoring, accessibility, and being a motivational force. For example, Thad described teachers at Dorothy Height Academy:

The teachers don't settle for lackluster grades. They will constantly get on any student who they know is failing. They will email them, they call parents, they will have parent teacher conferences, they make you stay after school, they will 
pull you to the side outside of class. They will also give you suggestions when you are struggling. They are relentless about our success.

Participants went in detail about specific teachers who influenced them and cared for them. One teacher in particular, known as Mr. Hayden, was noted to be a caring and influential mentor by 10 out of 15 participants. This teacher allowed participants to debate topics in class and presented them with multiple perspectives on world issues. Jaxon even attributed his reading abilities to Mr. Hayden stating "If it wasn't for him I wouldn't be in the place I am today. I wouldn't be at my reading level and even the way I think would not be where it is." Another participant corroborated this notion when he said, "He has really helped me see society in a different way. There is nothing that you can't really talk to him about that he won't really understand." Participants mentioned this teacher as someone they felt a close connection to, a mentor, and a teacher who helped them think differently. There were other teachers who participants also spoke about that pushed them beyond their limits, formed a bond with them, or taught curriculum in a manner that piqued their interest. When speaking of Mrs. Fulson, Jordan observed how she "pushed us in the classroom with the amount of material she gave us, which helped me in middle school and it still helps me now." Alex upheld this view of Mrs. Fulson when he noted, "She pulls out the best in you. She is the one who inspired me to go into engineering. She says I have a gift for math.” Each participant names multiple teachers who had significant impact on them and beamed with pride as they spoke about the relationships they have built with teachers. The level of influence many of the teachers have had on the participants was unmistakable. 
The administrators at Dorothy Height Academy were also a very influential group of people according to the participants. Every participant identified multiple administrators as shaping them in countless ways. Scholar Dominick explained,

Having administration and teachers who can actually attest to your success, and being able to stay after school to help you, meet you places to help you, administration having hands in your family issues, kind of gives you that cushion to be able to have a foundation and then just build all the way up.

Most notably, every participant spoke very highly of the founder of Black Males Working and Dean of Students at Dorothy Height Academy, Mrs. Atkins. Andre, whose mother passed away during his sixth grade year, credits Mrs. Atkins with saving his life. He spoke of the level of support she provided him during that time, including his most basic needs, and detailed a promise he made to Mrs. Atkins to honor his mother with his own life's accomplishments. The bond they share is undeniable and Andre accredits his turnaround from a truant student to a thriving scholar to Mrs. Atkins as he says, "Mrs. Atkins created a school that transformed me. She chose the right teachers and staff to make me a better man. I honestly don't know where I would be right now with her."

The program director, administrative dean, and community liaison for Dorothy Height Academy also received many accolades from the participants of this study. Students spoke of their dedication to the students and inspiration they provide. Xavier talked about the administrative team stating: "I call them the Connect Four. They literally work together as what us young people call them- a squad. They basically push all of us and they do all this stuff for us that we wouldn't even expect at a regular high school. It shows the love they have for us." The participants recognized and appreciated 
the hard work and dedication the administration shows, realizing that this is not the norm in their previously attended schools.

Another notable influencer was the participants' parents. "Parents" encompasses any adult who is helping to raise the participants. Many of them come from two-parent homes, some from single-parent homes, while grandparents or other family members are raising other participants. Regardless of the biological connection, the participants recognized the impact of caregivers and guardians on their success. Participants detailed their parents' involvement as evidenced through talking to teachers about grades, pushing them to reassess when necessary, and making the important decision for them to be a part of this school. Xavier calls his parents the "Law Enforcement" because he says they "lay down the law" in his education and life. Dominick's parents also play an enormous role in his education. He explained, "They stay on top of me, going to school, calling my teachers. They make sure they are engaged in everything I'm doing in school and it keeps me on my toes." Jaxon has the same experience with his grandmother. He describes her stating, "My grandmother makes sure my grades stay up. She takes me places, takes me to my internships and all the extracurricular activities so she keeps me up to par." For each participant, their parents were a crucial role in not only their education, but the trajectory of their lives in general.

The influencers of the participants have affected their personal beliefs, values, and their perceptions about life. These core principles hold major weight on the short- and long-term decisions these scholars make. The next section highlights the personal beliefs, values, and perceptions the participants share having attended Dorothy Height Academy. 


\section{Resulting Personal Beliefs, Values, and Perceptions}

The participants of this study have shared views concerning achievement, community, and their own self-images. They were able to speak candidly about their beliefs around these topics and common themes emerged as they shared their views. Regarding achievement, participant responses clustered around failure not being an option and affecting others. Concerning community and societal perceptions of them, they discussed the negative stereotypes often portrayed. The participants also discussed their own self-image that developed because of their experiences at Dorothy Height Academy and noted confidence, excellence, and resilience as notable characteristics they embody. A detailed account of each of their shared views follows:

When participants were asked about their views concerning achievement, the participants revealed that failure is not an option for them. Thad discussed the underlying assumption when attending Dorothy Height Academy as he said:

You are going to do something with your life, you're going to graduate from here, you're going to college, you're going to make money and you're going to come back here and do the same thing with the next generation. Basically, to be a Black male at this school means you are succeeding 100 percent.

When looking at the Scholar Handbook, observing interactions between scholars and staff, and through participant interviews, this sentiment is reiterated continually. Mason also confirms this notion as he notes, "Some people will see you as less than, you're not supposed to achieve as high as other people. But here, those expectations have gone out the window. The expectation here is greatness." Every participant discussed the high 
expectations the staff has for them in some capacity which has cultivated a culture where failure is not an option.

In order to avoid failure, however, supports must be in place. One of these supports, the culture of brotherhood of Dorothy Height Academy, helps scholars to maintain focus to achieve and also understand that influencing others is a component of their own achievement. Dominick reflected this concept as he noted, "It's more than just the suit and tie, or academics. We achieve when we are able to grow and enrich our brothers to have an impact on our school. This is something that I feel is essential here.” Donovan also believes in the brotherhood aspect as evidenced when he explained, "Here we see a lot of other people who look like you so that makes you want to help people and lift them up." The bond of the brotherhood helps to fortify the level of support available at Dorothy Height Academy.

The participants of this study were all well aware of the dominant narrative much of the community and United States society often has of them. The participants discussed this prevailing perception as if a source of motivation for them, a commission to prove others wrong. When asked how they think the community and society views Black males, the participants overwhelmingly presented, very candidly, negative stereotypes that exist. The following are some of their responses:

Alex-"They automatically see African American men as a negative thing, as predators, as something to be afraid of."

Dominick-“They say all Black males are thugs. I mean, just down to the hair. If someone has dreads, they are just automatically picked as drug dealer." 
Donovan-"Usually society sees us as achieving the bare minimum. But I've learned that even when we achieve the bare minimum, we are still getting unfair treatment from our white counterparts. We are actively disenfranchised."

Jeremiah-"I think the narrative for Black males is someone who is probably in the streets, not very intelligent, very aggressive, not good fathers."

Jordan-"Black males are perceived as lesser. They are seen as thugs, drug dealers, unintelligent people who are good for nothing other than shooting a basketball or scoring touchdowns." Joshua-“Black males are portrayed as gangster, people who do a lot murdering, being more deranged.”

Keon-“Black males are perceived as people who don't care about their families, only care about money, want to do drugs, steal."

Thad-"To be a Black male in society is to be constantly judged, everything you do or say is always looked at in a very negative light. You are never really understood by everyone else in the community. Shootings, gang attacks, robberies. It is how society paints us."

These forthright comments from the participants of this study provide perspective to the experience of being a Black male in the United States. Repeatedly the participants spoke of violence, criminality, and a lack of intelligence. In spite of the condemning portrayal of their demographics, the participants are in a positive, supportive environment that fosters a positive self-image. Their beliefs on the reality of their identity is the polar opposite of how society often portrays Black males.

When asked about their own self-image that results from attending Dorothy Height Academy and in spite of the way society may view them, participants responded 
with significantly positive narratives. They discussed having gained knowledge and pride concerning Blackness, confidence, and resiliency as a derivative of their experience at this school. Jordan shared:

I've learned to be proud that I'm Black and my eyes have been opened to the past people. I see what they've done and how they had success. Even though they might have struggled, their struggle was only temporary for that long-lasting success.

Mason echoed this thought as he said:

By being here I felt as if there is nothing wrong with being Black. Like, it's a gift. So, I feel they have helped promote positivity about being Black. I've learned my history and I am learning I came from greatness. Being who I am, I only expect to produce greatness.

His classmate Jeremiah appreciates the business aspect of the culture of the school and noted, "How they teach us to be very well-mannered and professional-that part helps me. It made me view myself as powerful and that I can do anything." In addition to those sentiments, Andre said, "This school taught me how to be tough and how life is going to throw you curve balls and you just got to be able to overcome it." Finally, Donovan shared an insightful commentary concerning his self-image:

This school allows me to be confident in my Blackness. It's okay to be African American and this school taught us from whence we came. If we teach other people our heritage, we can change the dominant narrative of American society of the African American male. 
The participants of this study revealed they are painfully aware of what society believes they are. However, they are confident and prepared to personify the counter narrative. Elements of their voices were also reflected in observations at the school. There is an obvious emphasis on celebrating African American culture through the visuals in the school. A large mural of Carter G. Woodson is painted in the foyer along with many of his inspirational quotes. Pictures and biographies of staff and community partners detailing their achievements are displayed on a bulletin board in the common area of the school. These seemingly small gestures contribute to the feeling of pride the participants described. Donovan noted, "When you know who you are and have an awareness of your ancestors' history, it is difficult for society to make you believe otherwise."

\section{Summary of Findings and Cross-Participant Analysis}

The following summary table indicates the themes and sub-themes that emerged. 


\section{Table 3}

Summary Table of Emergent Themes and Sub-Themes

\begin{tabular}{|c|c|c|}
\hline Theme & Sub-Theme & Example Response \\
\hline Defining Success & $\begin{array}{l}\text { 1a. More Than Grades } \\
\text { 1b. Resiliency } \\
\text { 1c. Helping Others } \\
\text { 1d. Best Effort } \\
\text { 1e. Investing Time } \\
\text { 1f. Gaining Knowledge }\end{array}$ & $\begin{array}{l}\text { I define success by just } \\
\text { trying to influence all your } \\
\text { friends around you, being a } \\
\text { good role model, working } \\
\text { hard, putting in extra time. }\end{array}$ \\
\hline School Experiences & $\begin{array}{l}\text { 2a. Brotherhood } \\
\text { 2b. Supportive } \\
\text { Environment } \\
\text { 2c. Opportunities } \\
\text { 2d. High Expectations } \\
\text { 2e. Growth }\end{array}$ & $\begin{array}{l}\text { They give us all these } \\
\text { opportunities that a regular } \\
\text { high school student } \\
\text { probably could not get. }\end{array}$ \\
\hline Influencers & $\begin{array}{l}\text { 3a. Teachers } \\
\text { 3b. Staff } \\
\text { 3c. Parents } \\
\text { 3d. Pastor }\end{array}$ & $\begin{array}{l}\text { The teachers play a major } \\
\text { role in helping me grow as } \\
\text { a person and encouraging } \\
\text { me. }\end{array}$ \\
\hline $\begin{array}{l}\text { Resulting Personal Beliefs, } \\
\text { Values, Perceptions }\end{array}$ & $\begin{array}{l}\text { 4a. Failure Is Not An } \\
\text { Option } \\
\text { 4b. Prove Them Wrong } \\
\text { 4c. Achievement } \\
\text { 4d. Pride }\end{array}$ & $\begin{array}{l}\text { We have set standards for } \\
\text { testing, we have all these } \\
\text { academic achievements. } \\
\text { We can raise the bar. }\end{array}$ \\
\hline
\end{tabular}

The themes displayed in this table serve to answer the essential research question of this study; which is, what experiences do high-achieving African American male high school students report as contributing factors to their academic success? Through indepth, individual interviews with students of the Dorothy Height Academy in the Champion School District, the participant's views are evident. They discussed their home life, experiences they have had a result of attending DHA, people who have influenced them while at DHA, as well as their subsequent goals, perceptions, and values. In speaking of the significance of various aspects of their lives, the participant narratives revealed that the school environment, the school's staff, and support from home enriched 
their experiences and fostered their success. The data from this study suggest attending school in this unique setting that demands high achievement through high expectations, offers college access, and provides relevant internship opportunities has positively influenced the success of all fifteen participants. Additionally, having a social support system including parents, guardians, teachers, and administrative staff positively influenced the participants' academic growth and personal development. Lastly, the participants reported that acquisition of knowledge around Black history fortified their self-identities and served as motivation for their goals and aspirations. Participant responses provided evidence of self-awareness of society's perceptions of Black males versus their own authentic identity. This countering of the dominant narrative around the lived experience of people of color supports the tenets of Critical Race Theory (Solorzano \& Yosso, 2002). In the final chapter, I discuss these findings in reference to implications for educators and policy-makers, and also make suggestions for future research. 


\section{CHAPTER FIVE DISCUSSION AND IMPLICATIONS}

In this chapter I discuss the findings of this study of high achieving African American males. These findings are examined in relation to the purpose of the study: highlighting the need to recognize counter-narratives as a framework for transforming the story and subsequent perceptions of African American males. In doing so, a brief review of the background and summary of the study is provided prior to discussion around the major findings and subsequent implications for policy and practice. Finally, this chapter concludes with opportunities for future research based on the findings of this study.

\section{Background and Summary of Study}

In this study, I explored how high achieving African American males report contributing factors to their success. Given there is an abundance of research on the underperformance of Black males (Brooms, 2016; Conchas \& Vigil, 2012; Fergus, Noguera, \& Martin, 2014; Harper \& Associates, 2014; Howard, 2014; Huerta, 2015; Milner, 2007), this study was necessary to also emphasize counter-narratives to the monolithic account of Black male achievement. Much attention is given to the deficits and inabilities of African American males, but there is a scarcity of research on the many African American males who are high achieving and successful against all odds (Harper \& Davis, 2012). This study sought to offer a glimpse into the perspectives of Black males who are on the opposite end of the achievement spectrum. Additionally, much of 
the research focuses on the underachievement of African American males does not include an account of African American males' personal thoughts on the topic (Howard, 2014). The lack of voice among Black males served as motivation for valuing the participant voice and their lived experience in this study. Therefore the participants, high achieving Black male students at a college preparatory school, offered insights into the reality of who they are and how their success became realized. Through consolidating their experiences and providing a venue for their own individual voices to be heard, the participants created a counter-narrative to the contrasting stories of Black male underachievement and offer rationale for how external and intrinsic factors have become a catalyst for their success.

The theoretical framework utilized in this study was Critical Race Theory (CRT). CRT seeks to identify, analyze, and transform aspects of education that uphold subordinate and dominant racial positions through the following five elements: (a) the centrality of race and racism and their intersectionality, (b) challenging dominant ideology, (c) a commitment to social justice, (d) the centrality of experiential knowledge, (e) the transdisciplinary perspective (Solorzano \& Ornelas, 2002). Challenging the dominant ideology of the uneducated African American male contributes to the purpose of my study and provides a platform to highlight the existing counter narratives. Critical Race Theory served as a backdrop for understanding the findings of this study as it relates to the centrality of race and racism in the realm of public education and challenging dominant ideology. The semi-structured interview questions were greatly influenced by the assumptions of CRT and allowed participants to provide their perspectives on race, self-identity, and the effects of such. (See Appendix B) The 
following section details the findings of this study and underlines the connectedness to the tenets of Critical Race Theory.

\section{Major Findings}

There were four overarching themes that emerged from the semi-structured interviews that included the manner in which participants (1) Define Success; (2) their School Experiences; (3) who they define as Influencers; and (4) their Resulting Personal Beliefs, Values, and Perceptions. These themes were discussed independently in Chapter Four to provide credence and to evidence of the cogency of each theme. Through the interdependence of these four themes, the major findings of this study were generated. The first of three major findings is a typology for success based on the perceptions of the participants. The second major finding is the responsibility each participant felt to challenge the dominant narrative. The third and final major finding is yielded from the sole research question: What experiences do high-achieving African American male high school students report as contributing factors to their academic success? The contributing factors these participants reported were their school experience and the influencers in their lives. Each finding is discussed independently in this section and evidence of each is provided through participant voice. Connectedness to the research literature is also offered.

Know Thyself: Responsibility to challenge the dominant narrative. The Critical Race Theory framework challenges dominant ideology that supports deficit theorizing (Solorzano \& Yosso, 2002). This tenet of the CRT framework was exemplified through the participants of this study. These high achieving African American males very vividly described the dominant societal view of who they are, as 
opposed to who they know themselves to be. As indicated in Chapter Four, every participant had a striking grasp on the perception much of society has of Black males. When asked, "What does it mean to be Black and male at this school? In your community? In the United States?” Donovan responded, “African American males undergo a struggle that's usually exclusive to us." Additionally, every participant suggested that the perception of a Black male in United States society is a thug, uneducated, and only good to play sports. The research literature also supports this notion as documented in Chapter Two. Harper and Davis (2012) state, "the images of Black men in our society often confine them to environments shaped by drugs, crime, athletics, and academic failure" (p. 103).

In contrast of this, however, was the participants' views on what it means to be a Black male at Dorothy Height Academy. At school, they view themselves as leaders, highly-educated, and impactful. So how does one navigate a world in which they are viewed in such negative light, and yet personify the very opposite core values? Collectively, the participants affirmed the sentiments of their classmate Noah as he discussed having a responsibility to "prove them wrong" in order to (according to Donovan), "change the dominant narrative of American society." Many of them spoke of the need to exceed expectations in order to get further in life. They were motivated by the low expectations society set for them and decided to "just be better than that" as indicated by participant Noah. Donovan added to that sentiment as he explained:

Usually society sees us as achieving the bare minimum. But I've learned that even when we achieve the bare minimum, we are still getting actively 
discriminated against, actively not getting the fair treatment from our peers, our white counterparts. We're actively disenfranchised.

This understanding of the effects of only achieving the bare minimum served as impetus to the overall feeling of responsibility to exceed expectations and achieve more than society would anticipate. It is also important to note that even in this positive, affirming environment, the participants are operating from a deficit mindset at times. Working from a perspective of 'prove them wrong' as opposed to 'prove them right' shows the fringes of deficit mindset still at play. Participants could have the mindset that they are proving their parents, administrators, teachers, and pastors right; instead of proving society wrong. There are many people rooting for and invested in their success, just as many may be guaranteeing their demise. Helping students and staff come to this realization is a benefit of this research.

The participants all possessed an observable knowledge of self that many attributed to the curriculum at Dorothy Height Academy. The curriculum provides multiple opportunities to learn African American history in general and specifically, notable African American males who have paved the way for them. One of the most notable figures many discussed was Carter G. Woodson, founder of Black History Month. They detailed his legacy and the impact of such on their own lives. They discussed how he set the standard and motivates them to prove society wrong. Jaxon spoke about how many do not know of Carter G. Woodson's legacy as he noted, "These are things that textbooks try to hide from us, the actual truth of who we are." The participants felt a responsibility to live out his legacy and teach others about the message of Carter G. Woodson to change how society thinks of Black males. Ironically, as each 
participant expressed their thoughts on the influence and impact of Woodson on their own success, as documented in Chapter Two, Dr. Carter G. Woodson (1933) expressed the following thoughts:

If you teach the Negro that he has accomplished as much good as any other race he will aspire to equality and justice without regard to race. Such an effort would upset the program of the oppressor in Africa and America. Play up before the Negro, then, his crimes and shortcomings. Lead the Negro to detest the man of African blood-to hate himself. With the truth hidden there will be little expression of thought to the contrary. (p. 88)

The participants of this study personify the counter narrative to the forewarning Carter G. Woodson defined in 1933 . His very life provides a decree for the participants to succeed against all odds. Yet, had they only paid attention to society's perception of them (crimes and shortcomings) it is almost certain that, as expressed by Woodson (1933), there would be little expression of thought to the contrary. The obligation they feel to challenge the dominant narrative was born in the very ancestor who they esteem. He only hoped such success would come to fruition for Black males in America and through these participants, the counter narrative is profound, tangible, and for them-a responsibility.

Contributing Factors to Success. The guiding research question of this study is, "What experiences do high-achieving African American male high school students report as contributing factors to their academic success?" In synthesizing the participants' responses to this question, each participant mentioned their experience at Dorothy Height Academy and people in their lives who have positively influenced them. The participants of this study attend school in a unique setting; one that is all-male, predominantly African 
American, and provides many opportunities to gain experiential knowledge. This distinctive situation has fostered a culture that embodies a strong brotherhood, supportive environment, high achievement, and pride. When participants described their school experience, they characterized it by discussing the strong relationships with staff and fellow students, high expectations, and unique opportunities. This experience, coupled with the influence of family and pastors made the difference for the participants. Dominick mentioned gaining integrity through his experiences at DHA, Jaxon noted a "push for excellence", Joshua described the ability to FaceTime his teachers when he needed help, and Xavier spoke of the tremendous impact of the brotherhood and study abroad educational opportunities. Every participant was adamant that the elements of their school experience contributed mightily to their success.

This notion of school experience having a vast impact is corroborated in the research literature. As depicted in Chapter Two, Brooms' (2016) study was very similar to this study of high achieving African American males at Dorothy Height Academy. The participants of Brooms' (2016) study were 20 Black male graduates of an urban secondary charter school and the study focused on the perceptions and experiences of these young men in relation to their academic success and further aspirations. The students attended Douglass Academy, a college-preparatory, single-sex school. All of the students identified belongingness, through school culture and relationships with teachers, as critical to their academic success (Brooms, 2016). The students also noted that Douglass embodied a positive school climate and environment and helped them to develop pride in themselves and their work. The welcoming and supportive atmosphere, access to college campuses, internships, and extra-curricular activities enhanced the 
students' self-efficacy. Brooms (2016) study corroborated the work of other researchers who have identified the value and importance Black males place on education (Harper \& Davis, 2012; Howard, 2014). This study validates Brooms' research of Black males at a single-sex, college preparatory academy.

In addition to the school experience, it was very evident that the influencers in the participants' lives played a major role in their success. These influencers were the participants' parents or guardians, the school staff, and in many cases, their pastors. Research literature suggests that African American parents are often perceived as lacking a desire to be involved, aloof, and uninterested (Allen, 2015; Rowley, Ross, Lozada, Williams, Gale, \& Kurtz-Costes, 2014). However, the counter narrative to African American parental involvement is occurring at Dorothy Height Academy. Every participant regarded parents or guardians as strict, having high expectations, and exhibiting involvement in school. One participant labeled his parents as "law enforcement" and another participant, Andre, discussed the passing of his mother during his sixth-grade year and the impact this had on him. Andre went on to detail the level of support he received and continues to receive from the school administrators and his "brothers" to ensure he is successful. He made a pact with the school administrators that he would do what it takes to be successful in order to honor his mother. The administrators reciprocally agreed to support him in every way possible to make sure this happened. As Andre discussed the passing of his mother and the resulting relationships he has developed at Dorothy Height Academy, he became overcome with emotion as he stated, "I'm doing it for her." Having parents who motivate the participants to achieve has been extremely influential for each participant. 
As with Andre, many times the school staff act as parents to the students by giving advice, support, and exposure to many different experiences. The participants spoke of many teachers and administrators who "have their back". Specifically, they noted the school staff pushes them beyond the average, offers multiple opportunities for tutoring, allows them to reassess when necessary, encourages them, show that they genuinely care, and do not settle for less than their best. Every participant named multiple people within the school that they know they can go to for any need. The research literature also supports this notion that the educator-student relationship has vast effects on student achievement. As detailed in Chapter Two, the relationships students experience and the resulting interactions have powerful effects on student self-efficacy and opportunity to learn (Allen, 2014). On the negative end of the spectrum, Black students experience poor relationships with teachers which often results in racial microaggressions masked as overrepresentation in special education and disproportionate suspension rates (Artiles 2003; Delpit 1995; Harry \& Klinger 2006; Milner, 2005; 2008). The opposing end of the spectrum, then, is personified daily at Dorothy Height Academy as students have positive, genuine relationships with staff and perform at high levels academically and behaviorally.

Another influencer named by participants was their pastor. After considering the history of Dorothy Height Academy and conducting observations at the school, this notion was not surprising. DHA was born out of the success of a Saturday enrichment program called Black Males Working (BMW). This enrichment program was created because the founder recognized the data concerning Black male achievement and their potential did not match. The founder created BMW to assist with the achievement of at- 
potential Black males and did so with the support of the church where she served as first lady. After the BMW program had been in operation for a two years, the school district began to realize that students who participated in the program were exceeding district performance on state assessments. The district therefore offered the founder of BMW the opportunity to open a school, which would be Dorothy Height Academy. The church also supported her as she opened this school and still has a key presence within the school currently. Black churches in America have historically and continue to currently play a major role in the moral, academic, and social development of Black youth in the battle to obtain equitable educational opportunities (Brown \& Gadson, 2010). BMW preceding Dorothy Height Academy is evidence of such and the voice of participants who value their pastors as important influencers is confirmation of the role the Black church plays in educating youth.

Furthermore, in conducting an observation at Dorothy Height Academy, I noticed that they would be hosting a symposium that included community leaders and pastors for a panel discussion on "The Black Church's Role in Public Education". I attended this symposium to gain insight as an observer. Prominent local pastors were invited into the school along with parents, community leaders, and educators for panel discussions around various facets of the church and its relevance to improving outcomes for youth. The students at Dorothy Height Academy served as school ambassadors, introduced speakers, gave tours, and were extremely engaged with the events of the day. This level of collaboration between the church and the school was reflective of the participants' belief that their pastors' influence was key to their success. The issue of achievement, especially for Black males must be addressed comprehensively through collaborations 
between churches, community organizations, and government entities (Brown \& Gadson, 2010).

The participants of this study were able to articulate the contributing factors to their success. To honor their collective voices on effectively educating African American males, their insights were sourced as a typology for successful African American male high school students. This both honors the voices of the participants as experts on the recipe for their own success and offers a blueprint for educators and policy-makers to use when planning and implementing programming for Black male high school students. The participants in this study offer the following four components as critical factors to the success of high achieving African American male high school students:

1. Defining success beyond grades and assessment scores through a focus on resiliency, helping others, putting forth effort, and gaining knowledge inside and outside the classroom.

2. Providing a school environment that promotes brotherhood, offers a supportive staff, and offers assistance with future goals.

3. Influential adult models who are invested in students beyond academics (i.e. administrators, teachers, parents, and pastors)

4. Instilling personal beliefs and values concerning achievement, self-worth, and cultural relativism.

Being attentive to this typology for the success of African American male high school students could assist in closing the achievement gap and improving educational outcomes for a historically marginalized group. Additionally, further detailed recommendations are offered to provide context for the findings of this research. 


\section{Recommendations}

The recommendations that follow are comprehensive but should not be viewed as an exhaustive list. There are a multitude of strategies that could be used to increase achievement and outcomes for Black males in the United States, however; the following recommendations are based on the research literature around high achieving African American males as well the current study at Dorothy Height Academy.

\section{Implications for Practice}

One key recommendation is rooted in the vital need for efforts to redress the contributing social environment of schools directly, intentionally, and consistently. Low expectations, high suspension rates, and deficit mindsets must be annihilated. Ford and Moore (2013) submit that African American males' low achievement is often a function of the social culture of the school with regard to attitudes, policies, and practices. This may manifest as low expectations, deficit thinking, racism, sexism, irrelevant curricula, as well as poor quality and culturally incompetent educators (Ford \& Moore, 2013). This is evidence that educators share responsibility for the achievement gap as much as factors outside of school and therefore cannot exonerate themselves from this role (Ford \& Moore, 2013). Therefore, the problems of underachievement and low achievement cannot be attributed solely to issues within the Black male student. Consequently, it is necessary to provide extensive training around culturally relevant pedagogy and mindsets in order to create supportive environments yielding positive relationships, academic support, a sense of belonging, and opportunities for exposure to the world outside the walls of the school. Development of culturally relevant pedagogy in conjunction with culturally relevant curricula, as observed and documented at Dorothy Height Academy, 
can foster the sense of belonging and self-esteem Black males need to persevere in a racist, counterproductive system and society.

A deeper aspect of this focus and training on the social environment of schools requires educators to take on a social justice commitment and approach to the education of African American males. This requires school leaders and educators to advocate for and fight alongside Black families for the rights of Black students (Ford \& Moore, 2013). Racism being present and pervasive in most school settings, it is imperative that students know and understand that they have advocates who are unapologetic about ensuring their success. According to Ford (2011), with substantive preparation and understanding of Critical Race Theory, school personnel can increase their own awareness of racism and its manifestations within school, then become self-reflective concerning their views and perceptions of African American males.

\section{Implications for Policy}

Additional recommendations to address the pervasive challenge of Black Male underachievement and low achievement come in the form of policy modifications. A key policy to address is the availability of affordable preschool and out-of-school programming. We must take a comprehensive and timely approach to education. This requires that from preschool to twelfth grade, quality educational experiences be coupled with after school and supplemental programming. The ETS Policy Evaluation and Research Center (2011) reports that the large gap between Black males and others exists before they ever start school and persists throughout their lifespan. In response to this epidemic, renowned children's rights activist Marian Wright Edelman asserted, "Children

are suffering from a toxic cocktail of poverty, illiteracy, racial discrimination and massive 
incarceration that sentences poor boys to dead-end and hopeless lives.” Ensuring a quality education beginning in preschool will help to close the gap before it widens to an irreversible point. During the critical preschool years, students develop cognitive, communication, and math skills, build social and emotional intelligence, and build foundation patterns for learning (Educational Testing Service, 2011).

The supplemental programming is also key to this plan, however. After school, summer, or weekend programming often provides the soft skills many students need that are not necessarily explicitly taught, as observed and documented of the Black Males Working Program that was the genesis of Dorothy Height Academy. In many cases, these programs teach students how to exist as a Black male in society. According to the Educational Testing Services' Policy Evaluation and Research Center, Brotherhood Sister Sol (BHSS) is an example of such supplemental programming. This evidence-based model has an emphasis on morality and ethics. Additionally, 85 percent of their students graduate from high school which is in high contrast to the 24 percent graduation rate of students in similar neighborhoods who do not attend a supplemental program (Educational Testing Service, 2011). After 15 years in service, not a single participant has been imprisoned. The co-founder is Khary Lazarre-White, who argued, "If you want to be a doc, go to med school. If you want to be a lawyer, go to law school. Where do you go to learn how to be a young man?" The BHSS is the answer to that question for many males who could otherwise fall prey to the social ills of the society. Programs such as Black Males Working and BHSS, coupled with quality education experiences from preschool to $12^{\text {th }}$ grade, are a crucial aspect of increasing achievement outcomes for all students, especially Black males. In spite of the poor outcomes many Black males 
endure, their situations are not permanent, unchangeable, or hopeless (Ford \& Moore, 2013).

An additional policy consideration is the use of single-sex and single-race schools as an intervention for African American males. The discussion of 'separate but equal' and the tenets of Brown $\mathrm{v}$ Board of Education have been debated persistently when considering the academic achievement gap and appropriate interventions. The research is distinct in determining that simply separating Black males from their white counterparts is not an effective intervention (Howard, 2014). However, intentional gender-based and culturally-relevant programming can increase achievement. Ascher's (1992) study reviewed a number of single-sex programs that aimed to address the underachievement of African American males. She highlighted five common features of these programs: The programs (1) provided appropriate same-sex role models and opportunities for same-sex bonding; (2) facilitated the transition into manhood through initiation rites; (3) provided cultural endorsement through a focus on self-identity, self-esteem, and development of academic values and skills; (4) increased parent and community involvement; (5) formed a safe haven for youth (Ascher, 1992). In summary, while separating Black males from their counterparts is not an effective intervention, having intentional, culturally relevant and affirming programming is a valuable intervention. Terry, Flennaugh, Blackmon, and Howard (2014) identify such schools as counterspaces. The term counterspace is derived from a Critical Race Theory concept and functionally defined as sites where deficit notions of people of color can be challenged and where positive collegiate racial climate can be established and maintained (Terry, Flennaugh, Blackmon \& Howard, 2014). These counterspaces can shield Black males from the marginalizing effects of 
urban schooling (Terry et al., 2014). Accordingly, while separate but equal is still inherently unequal, the focus, purpose, and rationale for single-sex, single-race schools should not be on equality, but equity.

Helping this marginalized group has advantages for the greater good as well. If policymakers are able to recognize and reflect on systemic structures and practices within the education system that are oppressive, changes to these systems to advance the cause of equitable education may be possible. Effective research-based strategies, such as equipping educators with culturally relevant pedagogy, mandated by policymakers may then translate to practitioners who can take the lead on implementation.

\section{Implications for Future Research}

The findings of this study of high achieving African American males validated the need to highlight counter narratives to the desolate account of Black males portrayed so prevalently in all forms of media. The counter narrative offers balance to otherwise monolithic stories often authored by individuals who are not Black males. There is an abundance of research on Black male underachievement and low achievement, however there is more research needed on high achieving African American males in order to replicate their success exponentially. This study conducted at Dorothy Height Academy featured students who attend school in a very unique setting. This site is characterized by the all-male, predominantly Black college preparatory culture. More research is needed in settings where high achieving African American males are thriving in a more traditional setting. Such studies may offer more generalizable strategies for successfully educating Black males. It is my supposition that even studies with settings in traditional schools will yield findings with social and cultural factors such as a sense of belonging 
and the necessity of culturally relevant pedagogy. However, more research is needed to triangulate and validate this data.

To further enhance the findings of this study, understanding the pedagogy and perspectives of teachers who work successfully with high achieving African American males would prove beneficial. To provide depth and breadth to the accounts of the participants, and to give voice to practitioners who have a wealth of knowledge, it would have been advantageous to interview teachers also. Participants expressed their thoughts on how much the teachers cared for and supported them. To show further appreciation for the voices of the participants, I would ask participants to suggest which teachers to interview concerning their pedagogy. It would be of interest to document the teachers' thoughts on how they demonstrate and cultivate a caring community and supportive environment. Teachers may be able to articulate specific strategies they use that students may not be able to identify directly, but feel the effects of indirectly. A major role of the educator is creating and facilitating social and academic experiences that are relevant for students. Allowing them to articulate the intricacies of this work could offer dimension to the findings of this study or future studies.

A final aspect to consider for future research is a methodological matter. Much of the research that has been conducted around African American male achievement has done so without the voice of African American males. Researchers, educators, and policy makers have made suggestions and created plans for increasing Black male achievement, yet the very subject of the research has been ignored, neglected, and overlooked. This is an injustice in and of itself. It is an absolute necessity that future research value the voice of Black males as a vital component to understanding their plight 
and subsequently improving their outcomes. I was surprised at the poignancy of their individual and collective voice during data collection and data analysis, but the clarity in which the participants spoke about their lives substantiated the need to always include their voice when appropriate for research. Going forward, not doing so could result in mere conjecture or assumption on their behalf.

\section{Conclusion}

Darden and Cavendish (2011) state, "Few proclaim that better resources, a tidier school building, better equipment, and a crackerjack curriculum are irrelevant. The ethical will should exist for equity to prevail, but action often does not follow words and sentiment" (p.67). African American males across the United States deserve an opportunity to learn in a manner that is conducive to their needs. EVERY student does. There are many African American males who are high achieving academically, so what are the factors contributing to these students' success? We can tell this story in a manner which facilitates replication of the experiences students hold valuable and consequently rewrite the narrative of African American males.

My research focused on honoring the voices of high achieving African American males to determine contributing factors to their success. This research was an effort to ensure equitable education for all students through qualitative analysis of current practices. The inadequate support of Black male students has negative influence that emerges in every facet of American society such as school, the work force, crime, and the economy (Terrell, 2017). Consequently, when we improve outcomes for African American males, we simultaneously improve societal norms. 
The stories of the 15 participants are not exclusive to them. They see the portrait that has been painted of themselves in the media and they concurrently enjoy the success that their school experience and influencers have provided. They endeavor to change the dominant narrative concerning Black males and they desire to ensure better outcomes for those coming behind them. As stated in Chapter 1, W. E. B. DuBois (1903) posed the question, "How does it feel to be a problem?" The problem DuBois referred to was that simply being a living, breathing, Black body which inevitably caused one to be viewed as an issue in American society (Terrell, 2017). One hundred fifteen years later, the participants of this study have a contrasting definition of what it means to be a "problem". They use the term emblematically and wear it as a badge of honor. For example, a student who scores an A on an assessment is a "problem". The athlete who ran the ball back for an 87-yard touchdown is a "problem". The professional earning a great living is a "problem". The irony of their colloquialism juxtaposed with DuBois' (1903) inquiry illustrates both growth and parallelism. The participants agree with much of society that they are a "problem", however, the connotation of the word has very different meanings for both. Likewise, both society and the participants recognize and acknowledge them as Black males, however; the implications of this are vastly different. These differences substantiate the need for counter narratives to be portrayed with as much frequency and publicity as the dominant narrative.

While working against the current deleterious propaganda about African American males, we must act with a sense of urgency to change school structures and mentalities that are detrimental to their success. It is imperative to cultivate supportive environments where culturally relevant pedagogy abounds and offer supplemental 
programming to ensure proper social development. It is also essential to centralize the voices of Black males in their own experiences to highlight existing counter narratives. It is my hope that bringing attention to counter narratives will help to change perspectives and shed new light on the potential of every Black male. These 15 participants and millions more of their cohorts are to be considered a "problem". 


\section{REFERENCES}

Adichie, C. N. (2009). The danger of a single story. New York, NY: TEDGlobal.

Allen, Q. (2015). “I'm trying to get my A": Black male achievers talk about race, school and Achievement. Urban Review, 47, 209-231.

Alexander, M. (2010). The new Jim Crow: Mass incarceration in the age of colorblindness. New York: New Press.

Artiles, A. (2003). Special education's changing identity: Paradoxes and dilemmas in views of culture and space. Harvard Educational Review, 73(2), 164-202.

Ascher, C. (1992). Successful detracking in middle and senior high schools. New York: ERIC Clearinghouse on Urban Education.

Bell, D. A. (1976). Serving two masters: Integration ideals and current interests in school Desegregation litigation. The Yale Law Journal, 85(4), 470-516.

Bell, D. (1987). And we are not saved: The elusive quest for racial justice. Basic Books.

Bonner, F. A. (2000). African American giftedness: Our nation's deferred dream. Journal of Black Studies, 30(5), 643-663.

Bonner, F. A. (2003). To be young, gifted, African American and male. Gifted Child 
Today, 26(2), 26-34.

Bonner, F. A., \& Bailey, K. W. (2006). Enhancing the academic climate for African American men. In M.J. Cuyjet (Ed.), African American men in college (pp. 2446). San Francisco: Jossey-Bass.

Bonner, F. A., Lewis, C.W., Bowman-Perrott, L., Hill-Jackson, V., \& James, M. (2009). Definition, identification, identity, and culture: A unique alchemy impacting the success of gifted African American millennial males in school. Journal for the Education of the Gifted, 33(2), 176-202.

Boykin, A.W., \& Allen, B. A. (2003). Cultural integrity and schooling outcomes of African American schoolchildren from low-income backgrounds. In P. Pufall \& R. Undsworth (Eds.), Rethinking childhood (pp. 104-120). New Brunswick, NJ: Rutgers University Press.

Brooms, D. R. (2015). “We Didn't Let the Neighborhood Win”: Black male students' experiences in negotiating and navigating an urban neighborhood. The Journal of Negro Education, 84(3), 269-281.

Brooms, D. R. (2016). "I was just trying to make it”: Examining urban Black males' sense of belonging, schooling experiences, and academic success. Urban Education, 1-27. doi: $\underline{10.1177 / 0042085916648743}$

Brooms, D. R. (2017). “They Don’t Really Care About Us”: Policing Black and Brown 
lives and futures. In S. E. Weissinger \& D. A. Mack (Eds.), Law enforcement in the age of Black Lives Matter: Policing Black and Brown bodies (pp. 137-148). Lanham, MD: Lexington Books.

Brooms, D. R. (2018). Being Black, being male on campus: Understanding and confronting Black male collegiate experiences. Albany, NY: SUNY Press.

Brown v. Board of Education, 350 U.S. 483 (1954).

Brown, E. L., \& Gadson, N. C. (2010). The critical role of Black religious institutions in the education of African Americans. In M. Dowson \& S. Devenish (Eds.), Religion and spirituality, (pp. 195-214). Charlotte, NC: Information Age Publishing, Inc.

Camera, L. (2016). Achievement gap between Black and white students still gaping. U.S. News and World Report. Retrieved from http://www.usnews.com/news/blogs/data-mine/2016/01/13/achievement-gapbetween-white-and-black-students-still-gaping

Coleman, J. S., Campell, E .Q., Hobson, C. J., McPartland, J., Mood, A. M., Weinfeld, F. D., \& York, R. L. (1966) Equality of educational opportunity. Washington D.C.: U.S. Government Printing Office.

Conchas, G. Q., \& Vigil, J. D. (2012). Streetsmart, schoolsmart: Urban poverty and the education of adolescent boys. New York: Teachers College Press.

Creswell, J. W. (2014). Research design: Qualitative, quantitative, and mixed methods approaches. Los Angeles: Sage 
Cushion, S., Moore, K., \& Jewell, J. (2011). Media representations of black young men and boys. Report of the REACH media monitoring project. London: DCLG.

Darden, E. C., \& Cavendish, E. (2011). Achieving resource equity within a single school district: Erasing the opportunity gap by examining school board decisions. Education and Urban Society, 44(1), 61-82.

Decuir, J. T., \& Dixson, A. D. (2004). "So when it comes out, they aren't that surprised that it is there": Using Critical Race Theory as a tool of analysis of race and racism in education. Educational Researcher, 33(5), 26-31.

Dei, G. S. (2003). Schooling and the dilemma of youth disengagement. McGill Journal of Education, 38(2).

Delgado, R., \& Stefancic, J. (2000). Critical race theory: An introduction. New York: New York University Press.

Delgado, R., \& Stefancic, J. (1993). Critical race theory: An annotated bibliography. Virginia Law Review, 461-516.

Delgado, R. \& Stefancic, J., Critical Race Theory: An Annotated Bibliography 1993: A Year of Transition (1995). University of Colorado Law Review, Vol. 66, 1995; U of Alabama Legal Studies Research Paper No. 2411634. Available at SSRN: https://ssrn.com/abstract=2411634

Delpit, L. (1995). Other people's children: Cultural conflicts in the classroom. New 
York: The New Press.

Dillard, C.B. (2000). The substance of things hoped for, the evidence of things not seen: Examining an endarkened feminist epistemology in educational research and leadership. International Journal of Qualitative Studies in Education, 13(6), 661681.

Dixson, A. D., \& Rousseau, C. K. (2006). Critical Race Theory in Education: All God's children got a song. New York: Routledge.

Du Bois, W. E. B. (1903). The Souls of Black Folk: Essays and Sketches. Chicago: AC McClurg and Co.

Dzaferagic, N. (2016). Self-fulfilling prophecy and stereotypes. Humanity in action John Lewis Fellowship. Symposium conducted at the meeting of National Center for Civil and Human Rights, Atlanta, Georgia.

Educational Testing Service. (2011). Addressing achievement gaps. Retrieved from http://www.ets.org/Media/Research/pdf/PIC-PNV19n3.pdf

Fergus, E., Noguera, P., \& Martin, M. (2014). Schooling for resilience: Improving the life trajectory of Black and Latino boys. Cambridge, MA. Harvard Educational Press.

Finn, J. D. (1989). Withdrawing from school. Review of Educational Research. 59(2). 117-142.

Ford, D. Y. (2011). Closing the achievement gap: Gifted education must join the battle. Gifted Child Today, 34(1), 31-34. 
Ford, D. Y., \& Milner, H. R. (2005). Teaching culturally diverse gifted students. Waco, TX: Prufrock Press.

Ford, D. Y., \& Moore, J. L. (2013). Understanding and reversing underachievement, low achievement, and achievement gaps among high-ability African American males in urban school contexts. Urban Review, 45, 399-415.

Fredrickson, G. (1981). White Supremacy. Oxford, UK: Oxford University Press.

Freeman, A. D. (1978). Legitimizing racial discrimination through anti-discrimination law: A critical review of Supreme Court doctrine. 62 MINN. L. REV, 1049, 1052119.

Gay, G. (2000). Culturally responsive teaching: Theory, research and practice. New York: Teachers College Press.

Gerring, J. (2004). What is a case study and what is good for? The American Political Science Review, 98(2), 341-354.

Gibbert, M., Ruigrok, W., \& Wicki, B. (2008). What passes as a rigorous case study? Strategic Management Journal, 29(13), 1465-1474.

Glesne, C. (2016). Becoming qualitative researchers: An introduction. Boston: Pearson. Goodenow, C., \& Grady, K. (1993). The relationship of school belonging and friends' values to academic motivation among urban adolescent students. The Journal of Experimental Education. 62(1), 60-71. 
Gordon, M. K. (2016). Achievement scripts: Media influences on Black students' academic performance, self-perceptions, and career interests. Journal of Black Psychology, 42(3), 195-220.

Groenewald, T. (2004). A phenomenological research design illustrated. International Journal of Qualitative Methods, 3(1), 42-55.

Hampton, F. M. (2014). The seven secrets of successful urban school students: The evidence continues to grow. Education and Urban Society. 48(5), 423-443.

Hammersley, M. (2000). Taking sides in social research. London: Routledge.

Harry, B., \& Klingner, J. (2006). Why are so many minority students in special education? Understanding race and disability in schools. New York: Teacher College Press.

Harper, S. R. (2015). Success in these schools: Visual counternarratives of young men of color and urban high schools they attend. Urban Education, 50(2), 139-169.

Harper, S. R., \& Associates (2014). Succeeding in the city. A report from the New York City Black and Latino Male High School Achievement Study. Philadelphia. University of Pennsylvania, Center for Study of Race and Equity in Education.

Harper, S. R., \& Davis, C. H. (2012). They (don't) care about education: A counternarrative on Black male students' responses to inequitable schooling. 
Educational Foundations, 26(1), 103-120.

The Hechinger Report. (2016). NCLB's legacy: With the Every Student Succeeds Act, have policymakers and educators learned from the past? Retrieved from http://hechingerreport.org/nclbs-legacy-essa-era-begins-policymakers-educatorslearned-past/

Heidegger, M. (1962). Being and time. New York: Harper \& Row.

Hernstein, J., \& Murray, C. (1994). The Bell Curve: Intelligence and class structure in American life. New York: Free Press.

Hooks, B. (2001). Salvation: Black people and love. New York: Harper Collins

Howard, T. C. (2014). Black male(d): Peril and promise in the education of African American males. New York: Teachers College Press.

Howard, T. C., \& Associates (2017). The counter narrative: Reframing success of high achieving Black and Latino males in Los Angeles County, Los Angeles: University of California, Los Angeles. UCLA Black Male Institute.

Huerta, A. H. (2015). "I didn't want my life to be like that": Gangs, college, or the military for Latino male high school students. Journal of Latino/Latin American Studies, 7(2), 156-167.

Husserl, E. (1970). Logical investigations. New York: Humanities Press.

Iverson, S. V. (2007). Camouflaging power and privilege: A critical race analysis of 
university diversity policies. Educational Administration Quarterly, 43(5), 586611.

Jenkins, T. S. (2006). Mr. Nigger: The challenges of educating Black males within American society. Journal of Black Studies, 37(1), 127-155.

Kohli, R. (2008). Breaking the cycle of racism in the classroom: Critical race reflections from future teachers of color. Teacher Education Quarterly, 35(4), 177-188.

Kirsh, S. J. (2010). Media and youth: A developmental perspective. Malden, MA: WileyBlackwell.

Labaree, D. (2010). Teach for America and teacher ed: Heads they win, tails we lose. Journal of Teacher Education, 61(1-2), 48-55.

Labaree, D. (2012). Someone has to fail: The zero-sum game of public schooling. Cambridge, MA: Harvard University Press.

Ladson-Billings, G. (1994). The dreamkeepers. San Francisco; Jossey-Bass Publishing Co.

Ladson-Billings, G. (1996). Silences as weapons: Challenges of a Black professor teaching White students. Theory into practice, 35(2), 79-85.

Laing, T., \& Brown, C. (2016). Constructing spaces for diverse Black masculinities in all-male public urban schools. Encyclopedia of Educational Philosophy and Theory. doi:10.1007/978-981-287-532-7_430-1

Lester, S. (1999). An introduction to phenomenological research. Taunton UK: Stan Lester Developments. 
Mann, H. (1848). Twelfth annual report to the Massachusetts Board of Education. The republic and the school: Horace Mann and the education of free men.

Marryshow, D. (1992). The impact of learning orientation on African American

children's attitude toward high achievers. Unpublished master's thesis, Howard University, Washington, DC.

McMillen, B. J. (2004). School size, achievement, and achievement gaps. education policy analysis archives, 12, 58.

Merriam, S. B. (1998). Qualitative research and case study applications in education. San Francisco, CA: Jossey-Bass.

Miles, M. B., Huberman, A. M., \& Saldana, J. (2014). Qualitative data analysis: A method sourcebook. CA, US: Sage Publications.

Milner, H. R. (2005). Stability and change in United States. Prospective teachers' beliefs and decisions about diversity and learning to teach. Teaching and Teacher Education, 21(7), 767-786.

Milner, H. R. (2007). Race, culture, and researcher positionality: Working through dangers seen, unseen, and unforeseen. Educational Researcher, 36(7), 388-400.

Milner, H. R. (2008). Critical race theory and interest convergence as analytic tools in teacher education policies and practices. Journal of Teacher Education, 59(4), $332-346$. 
Mishara, A. L. 1997. Binswanger and phenomenology. In Encyclopedia of phenomenology, ed. L. Embree et al. Dordrecht: Kluwer Academic Publishers. Montecinos, C. (1995). Culture as an ongoing dialogue: Implications for multicultural teacher education. In C. Sleeter \& P. McLaren (Eds.), Multicultural education, critical pedagogy, and the politics of difference (pp. 269-308). Albany: SUNY Press.

Morse, J. M., Barett, M., Magan, M., Olson, K., \& Spiers, J. (2002). Verification strategies for establishing reliability and validity in qualitative research. International Journal of Qualitative Methods, 1(2), 13-22.

Moustakas, C. (1994). Phenomenological research methods. Thousand Oaks, CA: Sage.

Nasir, S. N., McLaughlin, M.W., \& Jones, A. (2009). What does it mean to be African American? Constructions of race and academic identity in an urban public high school. American Educational Research Journal, (46)1, 73-114.

Noguera, P. A. (1997). Reconsidering the" crisis" of the Black male in America. Social Justice, $24(2$ (68), 147-164.

Noguera, P. A. (2003). The trouble with Black boys: The role and influence of environmental and Cultural factors on the academic performance of African American males. Urban Education, 38, 431-459.

Noguera, P. A. (2008). The trouble with Black boys and other reflections on race, equity, and the future of public education. San Francisco, CA: John Wiley \& Sons. 
Noguera, P. A., \& L. T. (2014). Risk, Resilience, and Response. In C. A. Grant \& E. Zwier (Eds.), Intersectionality and Urban Education: Identities, Policies, Spaces \& Power (pp. 79-96). Charlotte, NC: Information Age Publishing, Inc.

Palmer, R. T., Davis, R. J., \& Hilton, A. A. (2009). Exploring challenges that threaten to impede the academic success of academically underprepared African-American male collegians at an HBCU. Journal of College Student Development, 50(4), $429-445$.

Palmer, R. T., \& Young, E. M. (2009). Determined to succeed: Salient factors that foster academic success for academically unprepared Black males at a Black college. Journal of College Student Retention, 10(14), 465-482.

Plummer, K. (1983). Documents of life: An introduction to the problems and literature of A humanistic method. London: Allen \& Unwin.

Powell, K. (2007). Who's Gonna Take the Weight?: Manhood, race, and power in America. New York: Three Rivers Press.

Prier, D. (2017). The media war on Black male youth in urban education. New York, NY: Rutledge Research in Educational Equality and Diversity.

Quin, D. (2016). Longitudinal and contextual associations between teacher-student relationships and student engagement. Review of Education Research, 87(2), $345-387$.

Robinson, R. (2000). The debt: What America owes to Blacks. New York: Dutton Books. 
Rowley, S. J., Ross, L., Lozada, F. T., Williams, A., Gale, A., \& Kurtz-Costes, B. (2014). Framing Black boys: Parent, teacher, and student narratives of the academic lives of Black boys. In L.S. Liben \& R.S. Bigler (Eds.), The Role of Gender in Educational Contexts and Outcomes (pp. 301-332). San Diego, CA: Academic Press.

Sankofa, B. M., Hurley, E. A., Allan, B. A., \& Wade, B. A. (2005). Cultural expression black students' attitude toward high achievers. The Journal of Psychology, 139(3), 247-259.

Schneider, J. (2009). Privilege, equity, and the Advanced Placement program: Tug of war. Journal of Curriculum Studies, 41(6), 813-831.

Schott Foundation for Public Education (2012). The urgency of now: The Schott 50 state report on Black males and public education 2012. Cambridge, MA. Retrieved from www.blackboysreport.org/bbreport.pdf.

Schott Foundation for Public Education (2015). Black lives matter: The Schott 50 state report on public education and Black males. Cambridge, MA. Retrieved from http://blackboysreport.org/

Shenton, A. K. (2004). Strategies for ensuring trustworthiness in qualitative research projects. Education for Information 22, 63-75.

Simons, H. (2009). Case study research in practice. SAGE Publications.

Solorzano, D. G. (1997). Images and words that wound: Critical race theory, racial stereotyping, and teacher education. Teacher Education Quarterly, 24, 5-19.

Solorzano, D. G., \& Ornelas, A. (2002). A critical race analysis of advanced placement 
classes: A case of educational inequality. Journal of Latinos and Education, 1(4), 215-229.

Solorzano, D. G., \& Yosso, T. J. (2002). Critical race methodology: Counter-storytelling as an analytical framework for education research. Qualitative Inquiry, 8(1), 2344.

Stake R. E. (1995). The art of case study research. Thousand Oaks: SAGE Publications. Stanfield, J.H. (1995). The myth of race and the human sciences. Journal of Negro Education, 64, 218-231.

Stanley, L., Wise, S. (1993). Breaking out again. London: Routledge.

Sum, A., Khatiwada, I., McLaughlin, J., \& Palma, S. (2011). High school dropouts in Chicago and Illinois: The growing labor market, income, civic, social and fiscal costs of dropping out of high school. Boston: Center for Labor Market Studies, Northeastern University.

Taliaferro, J. D., \& DeCuir-Gunby, J. (2008). African American educators' perspectives on the advanced placement opportunity gap. The Urban Review, 40(2), 164-185.

Terrell, J. (2017, May 8 \{of post\}). Male educators of color are uniquely positioned to write a new narrative [Web log post]. Retrieved from http://www.therenewalproject.com/male-educators-of-color-are-uniquelypositioned-to-write-a-new-narrative-for-their-students/

Terry Sr, C. L., Flennaugh, T. K., Blackmon, S. M., \& Howard, T. C. (2014). Does the "Negro" still need separate schools? Single-sex educational settings as critical race counterspaces. Urban Education, 49(6), 666-697.

Thompson, A. (1997). For: Anti-racist education. Curriculum Inquiry, 27, 7-44. 
Toldson, I., \& Lewis, C. (2012). Challenge the status quo: Academic success among school-age African American males. Washington, DC: Congressional Black Caucus Foundation, Inc.

Venzant Chambers, T. T. (2011). Mergers and Weavers: Using racial opportunity cost to frame high-achieving African American and Latina/o students'school culture navigation styles. Journal of Educational Administration and Foundations, 22(2), 3-26.

West, C. (1993). Race matters. Boston: Beacon.

Wiggan, G. (2014). Student achievement for whom? High performing and still playing the game, the meaning of school achievement among high achieving African American students. Urban Review, 46(3), 476-492.

Wiggan, G., \& Watson, M. J. (2016). Teaching the whole child: The importance of culturally responsiveness, community engagement, and character development in high achieving African American students. The Urban Review, 48(5), 766-798.

Wojnar, D. M. \& Swanson, K. M. (2007). Phenomenology: An exploration. Journal of Holistic Nursing, 25(3), 172-180.

Woodson, C. G. (1933). The miseducation of the Negro. Washington, DC: The Associated Publishers. 
Wright, B. L., Crawford, F., \& Counsell, S. L. (2016). The other half hasn't been told:

African American males and their success in special education. Journal of African American Males in Education, 7(1), 35-51.

Yin, R. K. (2013).Validity and generalization in future case study

evaluations. Evaluation, 19(3), 321-332. 
Project Title:

\section{COUNTER NARRATIVES: A PHENOMENOLOGICAL STUDY OF HIGH ACHIEVING AFRICAN AMERICAN MALE HIGH SCHOOL STUDENTS}

Investigator(s) name \& address:

Co-Advisor and Principal Investigator:

W. Kyle Ingle, Ph.D.

College of Education and Human Development

University of Louisville

1905 South $1^{\text {st }}$ Street

Louisville, KY 40292

william.ingle@louisville.edu

De’Nay Speaks

University of Louisville

5114 Queens Castle Road

Louisville, KY 40229

denay.speaks@louisville.edu

Site(s) where study is to be conducted: University of Louisville, Fayette County Public Schools

Phone number for subjects to call for questions: W. Kyle Ingle (502) 852-6097

Introduction and Background Information

You are invited to participate in a research study. The study is being conducted by De'Nay Speaks. The study is sponsored by the University of Louisville, Department of Education Leadership, Evaluation, and Organizational Development. The study will take place at the University of Louisville and Fayette County Public Schools. Approximately 11 subjects will be invited to participate.

\section{$\underline{\text { Purpose }}$}

The purpose of this study is to explore the perspectives of successful African American male high school students concerning what they identify as factors contributing to their success.

\section{$\underline{\text { Procedures }}$}

In this study, you will be asked demographic information and information about our experiences with schooling in general. You will also be asked to provide responses to questions concerning your experience at Dorothy Height Academy specifically. Your participation will include an interview which will last up to 60 minutes in order to collect 
demographic and contextual information. The interview will be video and audio recorded. You may decline to answer any questions which make you feel uncomfortable.

\section{$\underline{\text { Potential Risks }}$}

There are no foreseeable risks other than possible discomfort associated with answering personal questions.

\section{$\underline{\text { Benefits }}$}

The possible benefits of this study to the participants include the opportunity to give voice to your perspectives concerning contributing factors to your success.

\section{Compensation}

You will not be compensated for your time, inconvenience, or expenses while you are in this study.

\section{Confidentiality}

Total privacy cannot be guaranteed. Your privacy will be protected to the extent permitted by law. If the results from this study are published, your name will not be made public. While unlikely, the following may look at the study records:

The University of Louisville Institutional Review Board, and the Human Subjects Protection Program Office. People who are responsible for research and HIPAA oversight at the institutions where the study is conducted, Government agencies, such as: Office for Human Research Protections (OHRP).

\section{$\underline{\text { Conflict of Interest }}$}

This study involves no foreseeable conflict of interest.

\section{Security}

All data will be stored on a password-protected computer and will be destroyed after the study is complete.

\section{Voluntary Participation}

Taking part in this study is voluntary. You may choose not to take part at all. If you decide to be in this study you may stop taking part at any time. If you decide not to be in this study or if you stop taking part at any time, you will not lose any benefits for which you may qualify.

You will be told about any changes that may affect you decision to continue in the study.

\section{U.S. Department of Education (DOE) Funded Studies}

Because this study is funded by the U.S. DOE or this school system receives funding from the DOE, we are required to tell you the following information. 
The information we collect from the study may only be used to meet the purposes of the study as stated in this consent. We will conduct this study in a manner that does not allow identification of you by anyone other than study team members or others who may have a legitimate reason to know. All instructional materials or survey instruments used for the research are available for you to see before the study begins if you ask to see it. If you want to see any of this information, please contact De'Nay Speaks, (859) 421-0750 and they will give you a date and time where it will be available for you to review. Once we have completed this study, we required by the U.S. Department of Education to destroy or return to the school system all personally identifiable information when no longer needed for the purposes of the study. All digital recordings will be destroyed by 2019 and all digital transcriptions will be destroyed by 2026.

Contact Persons, Research Subject's Rights, Questions, Concerns, and Complaints

If you have any concerns or complaints about the study or the study staff, you have three options.

You may contact the principal investigator at (502) 852-6097 or william.ingle@louisville.edu

If you have any questions about your rights as a study subject, questions, concerns, or complaints, you may call the Human Subjects Protection Program Office (HSPPO) (502) 852-5188. You may discuss any questions about your rights as a subject, in secret, with a member of the Institutional Review Board (IRB) or the HSPPO staff. The IRB is an independent committee composed of members of the University community, staff of the institutions, as well as lay members of the community not connect with these institutions. The IRB has reviewed this study.

If you want to speak to a person outside the University, you may call 1-877-852-1167. You will be given the chance to talk about any questions, concerns, or complaints in secret. This is a 24-hour hot line answered by people who do not work at the University of Louisville.

\section{Acknowledgement and Signatures}

This informed consent document is not a contract. This document tells you what will happen during the study if you choose to take part. Your signature indicates that this study has been explained to you, that your questions have been answered, and that you agree to take part in the study. You are not giving up any legal rights to which you are entitled by signing this informed consent document. You will be given a copy of this consent form to keep for your records.

Subject Name (Please Print)

Printed Name of Legal

Representative (if applicable)
Signature of Subject

Date Signed $\overline{\text { Signature of Legal Representative }}$ $\overline{\text { Date Signed }}$ 
Relationship of Legal Representative

to Subject

Printed Name of Person Explaining Signature of Person Explaining

Date Signed

Consent Form

Consent Form (if other than the

Investigator

Printed Name of Investigator

Signature of Investigator

Date Signed

List of Investigators

Phone Numbers

W. Kyle Ingle

(502) 852-6097

De'Nay Speaks

(859) 421-0750 


\section{SUBJECT ASSENT}

Counter Narratives: A Phenomenological Study of High Achieving African American Male High School Students

I am invited to be in a research study being done by Mrs. De'Nay Speaks. When a person is in a research study, they are called a "subject". I am invited because I have been a student at Dorothy Height Academy since the $6^{\text {th }}$ Grade, I am a member of the class of 2019, and I have a grade point average of 3.0 or above.

This means that I will participate in an interview about my experiences at Dorothy Height Academy. There may be some risks with this study. These risks are that sharing personal information may cause me to feel uncomfortable.

This study will last for one hour. The benefit to me for participating in this study is that I get to share my perspectives and opinions. My voice will be heard.

My family, Dorothy Height administrators, and Mrs. De'Nay Speaks will know that I'm in the study. If anyone else is given information about me, they will not know my name. A number or initials will be used instead of my name.

I have been told about this study and know why it is being done and what I have to do. My parent(s) have agreed to let me be in the study. If I have any questions I can ask Mrs. De'Nay Speaks. She will answer my questions. If I do not want to be in this study or I want to quit after I am already in this study, I can tell the researcher and she will discuss this with my parents.

Printed Name of Subject

Signature of Subject

Date Signed

Printed Name of Parent/Guardian

Printed Name of Investigator

Signature of Investigator

Date Signed 


\section{APPENDIX B: INTERVIEW PROTOCOL}

I will be asking you some questions about your experience with school in general and Dorothy Height Academy, specifically. Before we get into technical questions, please tell me about yourself including your goals, aspirations, hobbies, and what makes you "you".

\section{Questions}

1.) How do you define "success" in school?

2.) Describe the process for deciding to attend Dorothy Height Academy. (DHA) -What made you stay at DHA?

3.) How did you perform academically prior to attending DHA? -After?

4.) What was it like at DHA during the first year you were enrolled?

5.) Has DHA made an impact your academic success? If so, how? -If you had not attended DHA, how might this have impacted your trajectory?

6.) What would you attribute your overall academic success to?

7.) What role do your parents play in your education?

8.) What organizations and/or extra-curricular activities do you participate in?

9.) What role do the teachers of DHA play in your success? (School leaders, Staff) -Tell me about the staff who has had the most impact.

10.) What does it mean to be Black and male at DHA? In your community? In the United States?

11.) Compare or contrast this perception with your own self-image.

12.) What influence has DHA had on the way you view yourself? (Other African 
American males, the world)

13.) What else would you like to share about yourself? 


\section{APPENDIX C: RESEARCHER POSITIONALITY}

According to Dillard (2000) and Stanfield (1995), African Americans are misrepresented, exploited, silenced, and taken for granted in education research throughout history. As Milner (2007) asserts, many researchers and people of color may have been kidnapped in to believing that African Americans are inferior and thus may concentrate on negative attributes of people and communities of color. Similarly, an abundance of research has been conducted on the achievement gap, its causes, and cures. The bulk of this research typically focuses on low-achieving students of color in an attempt to identify root causes and solutions. Research focused on high-achieving students of color and the factors contributing to their success is limited, however. This disparity in research compels me to pinpoint contributing factors which positively influence African American students to be high-achievers in order to perpetuate a counter-narrative and help educators replicate these elements across multiple settings. This could decrease the disproportion of success between African American students and their counterparts.

My research is an effort to focus on contributing factors to the success of highachieving African American males. In this qualitative study, I will highlight the need to recognize counter-narratives as a framework for transforming the story and perceptions of African American males. The need to tell a more complete story of Black males is paramount to their success. There is no voice more poignant and qualified to tell the story of high academic achievement in the face of an adverse system than African American males. Therefore, the following research question will guide the purpose of this 
study: What experiences do high-achieving African American male high school students report as contributing factors to their academic success?

When conducting research, it is absolutely necessary to reflect on your positionality as a researcher. Positionality can determine or influence every aspect of the research such as the topic, interview questions, perceptions about participants, or the way in which you code data. Therefore, it is imperative that researchers are fully aware of their own position in relation to the study. In particular, when researching people of color, one must ensure that their own biases do not impede the research process. Milner (2007) suggests that researchers be actively engaged, thoughtful, and forthright regarding possible tensions that can arise when conducting research around people of color. Milner (2007) also advocates for the pursuit of deeper racial and cultural knowledge about self and the community that is being studied in order to accurately interpret and validate the experiences of participants. As I conduct research, it is necessary that I consider my positionality as an African American woman who is a mother of African American boys and married to an African American male. My own perceptions and beliefs regarding how the world should view my sons and husband undeniably fuels my research interests but that has to be tempered with awareness in order to avoid dangers seen, unseen, and unforeseen (Milner, 2007).

A framework to guide researchers in the process of racial and cultural awareness, consciousness, and positionality through the education research process was outlined by Milner (2007). This framework includes researching the self, researching the self in relation to others, and shifting from self to system. The following will detail my own positionality in relation to the aforementioned framework. 


\section{Researching the Self}

West (1993) contended that it is difficult to advocate for someone else's emancipation without being emancipated yourself. Evaluating the self is a form of such emancipation. In examining my identities, first and foremost, I am African American. I also identify as Black. This impacts the way in which I navigate the world infinitely. I am never separate from this identity. My ancestors were slaves, but I am also aware that this place of lowliness is not the origination of my people. It is rather the opposite: I come from a lineage of African kings and queens and I am absolutely proud of this heritage! This identity keeps me mindful of the struggle and plight of African American people so I never take my privileges for granted. This identity is also a reminder of how strong my ancestors were which is a motivator and source of my own strength.

Understanding the history of Black people in America inspires my desire to champion against the oppression and marginalization of African American people. The narrative that exists in the United States today which regards African American people, males in particular, as violent, unintelligible, and lazy literally disturbs my very instincts. This narrative provokes a visceral response because I am aware of who I am, whose I am, and who I came from. Allowing anyone to diminish this identity is genocide.

An additional layer of my identity is that I am an African American women. Historically, woman have been a subordinate gender. However, I have been blessed to be raised around many female leaders and I am a leader as well. Beyond being an African American woman, I am also a Christian, an educational leader, a wife, and a mother. All of these identities shape my beliefs, perceptions, and subsequent actions. 
As an administrator in a large, urban, school district that struggles to educate African American males effectively, I have always been perplexed by the focus on the ever-growing achievement gap between white students and their counterparts. As a mother of three flourishing African American males, a wife to one successful African American male, a daughter of a positive African American male, a sister-in-law to a productive African American male, and an aunt to two thriving African American males, my view of the accomplishments, potential, and capabilities of the African American male contradicts the narrative portrayed so prevalently. To embrace the notion that African American males are somehow predestined, biologically or otherwise, to achieve less than their peers is to succumb to a deficit mindset perpetuating failure every day in schools. I refuse. My greatest sensibilities indicate such factors as environment, relationships, inclusive systems, and culturally-responsive pedagogy have a vast effect on the achievement of any student; and most notably those who are disenfranchised. Therefore, my research is my quest to identify the factors which contribute to the achievement of African American males by listening to the voices of successful African American males. Milner (2007) suggests that researchers should possess or pursue deeper racial and cultural knowledge about themselves and the community or the people they are studying. This process of racial and cultural consciousness as research is conducted affirms the tenets of Critical Race Theory and is the basis of my research.

A major cultural facet of my identity is Christianity. I was raised in a Baptist church and continue to practice this religion as an adult. Singing hymns, many of which were written during times of oppression, really instilled the level of turmoil African Americans experienced and how they triumphed by faith in an ever-present, all-powerful 
God. The legacy of such faith is engrained in who I am and causes me to persist in spite of many trials. I recognize this same persistence as I study African American males. There is no group of people more marginalized and demonized than Black men. The ability to persevere and succeed in the face of pervasive racist systems, structures, and mindsets is nothing short of a miracle from God. This connection between the Black church and constituents was further reified for me as I participated on a panel discussion concerning how the Black church can support improving education for students of color. I listened to students speak about programs they participate in through various churches and how these programs have impacted them at school. One program in particular that was represented during the panel discussion, Black Males Working (BMW) Academy, is near and dear to me because it was born out of the church I grew up in. The pastor's wife (one of the fierce female leaders I try to emulate) founded BMW because she recognized that the data and the potential didn't match. She is a retired teacher and decided to take action on behalf of African American males to create a program that empowered these young men through college visits, lectures, etiquette classes, ACT prep, tutoring, and cultural trips. The church supported the program which has now blossomed to serve hundred African American males across four different churches. The school district eventually realized the effect BMW was having on the males in the program and partnered with them to create a school that would emulate the same principles and strategies. This school is Carter G. Woodson Academy, where I hope to conduct my research. My positionality has definitely been effected by experiences the growth of the BMW program into Carter G. Woodson Academy. 


\section{Researching the Self in Relation to Others}

The second part of the framework on race, culture, and positionality (Milner, 2007) is for researchers to reflect about themselves in relation to the people and communities involved in their research. This allows researchers to acknowledge the positions, roles, and identities they bring to the research process. At times a researcher's interest can overshadow the interests of the participants (Milner, 2007). Accordingly, interests are negotiated in this portion of the framework in pursuit of interest convergence. Milner (2007) also asserts that truth is defined as what is real and thus meaningful and "right" for the research or participants. These truths are shaped by experiences and the way in which we interpret these experiences. There everyone has their own "life world" and researchers have to navigate the terrain as such. Milner (2007) discusses possible situations where the life world of an African American researcher may be inundated with racism and injustice which could enable or disable the researcher's efforts to understand the specifics of certain situations. In these situations, it may or may not be a beneficial for the researcher to be of similar race and culture as the participants. Consequently, this second part of the framework suggests that researchers reflect on themselves in relation to others, recognize and work through the commonalities or possible tensions which may arise, and negotiate how this will effect interactions with participants (Milner, 2007).

The participants in my study are African American males. We share cultural backgrounds and historical landscapes. The common experience provides a foundation for a positive researcher-participant relationship. The glaring difference between myself and the participants is that I am female while they are all males. This characteristic is one 
that forces them to navigate this world differently than I do. The manner in which they carry themselves can literally determine life and death. If they appear to be too "urban" by wearing hoodies, sagging pants, or sporting untamed hair, many in the United States will perceive them as thugs. Unfortunately, this perception has literally proved fatal for such African American males as Trayvon Martin, Tamir Rice, or Philando Castile, just to name a few. The participants in my study attend a school that works to rewrite the narrative of what it means to be a successful African American male. They follow the "Well Principles" which include being well dressed, well-traveled, well spoken, well mannered, well behaved, and well-read which will lead them to be well-prepared for college, career, and life. Subscribing to these practices and beliefs shape their behaviors as they navigate the world but also provides depth to their character as they grow from boys to men.

I feel very connected to the participants in my study. The school they attend was birthed out of the church I grew up in. The leaders of the school are the same female leaders I watched as a child and who I have modeled my own leadership after. I am mother to three boys who would likely be students at this school if I moved back to that city. This connectedness will hopefully allow the participants to feel comfortable enough to be candid, open, and honest during interviews.

Many of the participants in my study have formed a Student Government Association and worked to host an institute during Black History Month called the Dr. Carter G. Woodson Institute: Leadership, Education, Equity, and Race Relations in America. This institute included a weekly lecture series including the following topics: “The Mis-Education of the Negro", "Why I am Treated Differently", "I Kneeled and the 
President Called Me a Traitor", and "2 Bey or Not Two Be". The lecture series tackled a number of challenging cultural and societal issues directly related to and effecting African American males. Professors from local universities and community leaders came to speak to the students and engage in meaningful discourse around these topics. I can only imagine the impact events such as these have had on the participants in my study but I am certain their positionality and self-perceptions have changed as a result. Participant's truths depend on how they have experienced the world (Milner, 2007), and these truths have definitely changed by attending Carter G. Woodson Academy.

My research interests are beneficial to not only contribute to the body of knowledge concerning Black males in education research, but can also be advantageous for the participants of my study by giving them the opportunity to name their own realities. This is an authentic form of interest convergence which is mutually valuable for everyone involved.

\section{Shifting From Self to System}

The final feature of Milner's (2007) framework for race, culture, and positionality is a recommendation that researcher's contextualize their new and expanded consciousness to juxtapose that with historic, political, social, economic, racial, and cultural realities on a larger scale. This portion of the framework requires a shift from a focus on more personalized issues to consider policy and systems which may be fundamental to the issues. This shift from self to system allows researcher to avoid the dangers of minimizing the permanence and pervasiveness of race and racism because they don't view themselves as racists (Milner, 2007). It is difficult to defend against that which you don't believe exists in your "life world". Therefore, a shift to look at systems 
can move researchers beyond their own experience and allow them to view the salience of race and racism, consequently assisting them in situating their research in a broader context.

Race, racism, and culture are a major component of my research participants' everyday lives. As African American males, they have to take their intersectionality into consideration constantly as they interact with others. The participants in my study are at a point in their lives where they may just now be realizing the way in which many perceive them in United States. Recent events such as the killing of unarmed Black males, the subsequent ostracizing of Colin Kaepernick, the realization of what the verses of The National Anthem say, and the election of a president with racist tendencies weighs heavily on the participants in my study. Who Black males are portrayed to be in the media and who my research participants know themselves to be are far from the convergent. Therefore, the very purpose of my study is to highlight successful African American males in the face of a deleterious, toxic narrative that is pervasive throughout the systems of this country.

The literature concerning African American males in education is very telling. Since the (1966) seminal research of James Coleman, a sociologist authoring an educational equity report examining the inequities of educational opportunities throughout the United States and especially the South, the conclusions concerning African American males have been bleak. This report, mandated by the Civil Rights Act of 1964 and later dubbed the Coleman Report, had major flaws in methodology yet laid the foundation for emphasizing the disparities in educational practice between racial and ethnic groups (Camera, 2016). Over 50 years later, the achievement gap persists despite 
the myriad of research which has been conducted on this topic. However, while there is definitely much work to be done, there is growing evidence of successful African American students who are exhibiting resilience and excellence.

In an effort to transform this 50-plus year old narrative, the Schott Foundation (2012), insists Black males in America have been cast in a far too negative light given their contributions to family, community, democracy, economy, thought leadership, and country. This narrative has become prevalent due to a focus on the deficits of the American school system. While these deficits are important to highlight because they shed light on the many inequities facing students of color; it is also important to emphasize the counter-narrative to underscore the resiliency being displayed by many students across this country.

Toldson and Lewis (2012) found that although many have reported Black males are underrepresented in colleges and universities, in actuality Black males' representation is proportionate to their representation in the general population. Unfortunately, only $16 \%$ of black males hold college degrees, compared to $32 \%$ of white males, they are 2.5 times less likely to be enrolled in gifted and talented programs, even if their prior achievements reflect the ability to succeed; three times more likely to be suspended or expelled from school than their white peers, therefore missing valuable learning time; less likely to graduate from high school in four years than their white peers and twice as likely to drop out of high school as their white peers. This study exhibits many of the overwhelming obstacles many African American males must overcome in order to be successful. 
There is copious research detailing the underachievement of African American males and suppositions about strategies to decrease the achievement gap. Much focus and attention has been given to the problems facing African American males, yet very little consideration has been devoted to their success. As a researcher, this serves as a call to action to determine how to increase the number of high achieving African American students across the United States of America.

African Americans have struggled for every ounce of success they have earned in the United States. The weight of such an existence is carried in various ways by every African American. For some, a will to be successful and beat the odds is ignited. For others, the emotional weight is difficult to navigate and at times proves unbearable. Regardless, the vast systemic and organizational barriers must be eradicated in order for the United States to be able to genuinely make progress. 


\section{CURRICULUM VITAE}

De'Nay L. Speaks

Email: denay.speaks@gmail.com

Education

UNIVERSITY OF LOUISVILLE-LOUISVILLE, KY

- Doctor of Education (Education Leadership and Organizational Development), December, 2018

UNIVERSITY OF LOUISVILLE - LOUISVILLE, KY

- Education Specialist (Supervision of Instruction), December 2012

- Principal Certification

UNIVERSITY OF LOUISVILLE - LOUISVILLE, KY

- Master of Arts in Teaching, May 2005

- Teaching Certification

UNIVERSITY OF LOUISVILLE - LOUISVILLE, KY

- Bachelor of Arts in Psychology, December 2003

Professional Leadership Experience

Principal Pipeline Cohort, JCPS (January 2018-June 2018)

- Cultivate principal leadership skills through a rigorous program consisting of shadowing, observation, and literature-based learning

Assistant Principal, Wellington Elementary School, JCPS (August 2014-present)

- Exhibit Instructional Leadership skills through facilitation of school-wide programming

- Implement and manage school-wide discipline procedures

- Collaborate with Principal to create and manage school-wide systems

Goal Clarity Coach, Wellington Elementary School, JCPS (August 2012-August 2014)

- Facilitated professional development to initiate and implement Professional Learning Communities effectively

- Facilitated school-wide curriculum programming for Tier 1, 2, and 3 students

- Served as KTIP Resource Teacher

- Analyzed assessment data

Resource Teacher, Student Development Services, JCPS (July 2011-August 2012)

- Developed and facilitated district-wide and school-based professional development to assist teachers in implementing social-emotional curriculum

- Analyzed school data to determine impact of CARE For Kids philosophy 
- Completed training in Developmental Discipline and Responsive Classroom

- Completed "The Skillful Teacher" training by Jon Saphier

Staff Developer, Breckinridge-Franklin Elementary, JCPS (July 2010-July 2011)

- Developed and facilitated professional development

- Facilitated the launch of KCAS Standards through professional development

- Compiled and evaluated data

- Completed training by Math Solutions

- Modeled Lessons

- Created an intervention schedule and administered interventions

Classroom Teacher, Breckinridge-Franklin Elementary, JCPS (July 2005-June 2010)

- Designed, Planned, and Implemented Instruction

- Provided embedded professional development

- Implemented CARE For Kids Philosophy and Served on the CARE for Kids Leadership Team

- Served on the Instructional Leadership Team, Site Based Decision Making Council, Interview Committee, and Magnet Design Team

- Served as the Intermediate Team Leader and Writing Cluster Leader

\begin{tabular}{ll}
\hline & Conference Speaker Experience \\
\hline October 10, 2017 & $\begin{array}{l}\text { Tuscaloosa City Schools, School Achievement Institute } \\
\text { Session: Dive in the Deep End: Deeper Learning for } \\
\text { Diverse Learners }\end{array}$ \\
June 9, 2017 & $\begin{array}{l}\text { Jefferson County Public Schools, Deeper Learning } \\
\text { Symposium Session: Culturally Responsive Practices }\end{array}$ \\
August 27, 2016 & $\begin{array}{l}\text { Tuscaloosa City Schools, Closing the Opportunity Gap } \\
\text { Session: Developing Culturally Responsive Teachers }\end{array}$ \\
November 3, 2015 & $\begin{array}{l}\text { Christian County Schools, Closing the Opportunity Gap } \\
\text { Session: The Perfect Storm: PBIS + Restorative Practices } \\
+ \text { CRT }=\text { Success }\end{array}$
\end{tabular}

